\title{
PPAR $\alpha$ activation is essential for HCV core protein-induced hepatic steatosis and hepatocellular carcinoma in mice
}

\author{
Naoki Tanaka,1,2 Kyoji Moriya, ${ }^{3}$ Kendo Kiyosawa, ${ }^{2}$ Kazuhiko Koike, ${ }^{3}$ \\ Frank J. Gonzalez, ${ }^{4}$ and Toshifumi Aoyama ${ }^{1}$ \\ ${ }^{1}$ Department of Metabolic Regulation, Institute on Aging and Adaptation, Shinshu University Graduate School of Medicine, Matsumoto, Nagano, Japan. \\ 2Division of Gastroenterology, Department of Internal Medicine, Shinshu University School of Medicine, Matsumoto, Nagano, Japan. \\ 32Department of Infectious Diseases, Internal Medicine, Graduate School of Medicine, University of Tokyo, Tokyo, Japan. \\ ${ }^{4}$ Laboratory of Metabolism, National Cancer Institute, NIH, Bethesda, Maryland, USA.
}

\begin{abstract}
Transgenic mice expressing HCV core protein develop hepatic steatosis and hepatocellular carcinoma (HCC), but the mechanism underlying this process remains unclear. Because PPAR $\alpha$ is a central regulator of triglyceride homeostasis and mediates hepatocarcinogenesis in rodents, we determined whether PPAR $\alpha$ contributes to $\mathrm{HCV}$ core protein-induced diseases. We generated PPAR $\alpha$-homozygous, -heterozygous, and -null mice with liver-specific transgenic expression of the core protein gene $\left(\mathrm{Ppara}^{+/+}: \mathrm{HCVcpTg}, \mathrm{Ppara}^{+/-}: \mathrm{HCVcpTg}\right.$, and $\mathrm{Ppara}^{-/-}: \mathrm{HCV} \mathrm{CPTg}$ mice. Severe steatosis was unexpectedly observed only in $\mathrm{Ppara}^{+/+}: \mathrm{HCV} \mathrm{CpTg}$ mice, which resulted from enhanced fatty acid uptake and decreased mitochondrial $\beta$-oxidation due to breakdown of mitochondrial outer membranes. Interestingly, HCC developed in approximately $35 \%$ of 24 -month-old $\mathrm{Ppara}^{+/+}$: HCVcpTg mice, but tumors were not observed in the other genotypes. These phenomena were found to be closely associated with sustained PPAR $\alpha$ activation. In Ppara ${ }^{+/-}:$HCVcpTg mice, PPAR $\alpha$ activation and the related changes did not occur despite the presence of a functional Ppara allele. However, long-term treatment of these mice with clofibrate, a PPAR $\alpha$ activator, induced HCC with mitochondrial abnormalities and hepatic steatosis. Thus, our results indicate that persistent activation of PPAR $\alpha$ is essential for the pathogenesis of hepatic steatosis and HCC induced by HCV infection.
\end{abstract}

\section{Introduction}

$\mathrm{HCV}$ is one of the major causes of chronic hepatitis, whereas patients with persistent $\mathrm{HCV}$ infection have a high incidence of hepatocellular carcinoma (HCC) $(1,2)$. Occurrence of HCC associated with chronic $\mathrm{HCV}$ infection has increased over the past 2 decades (3-5), and chronic HCV infection is recognized as a serious debilitating disease. However, the mechanism in which chronic HCV infection mediates hepatocarcinogenesis remains unclear.

$\mathrm{HCV}$ core protein was shown to have oncogenic potential (6). To examine how HCV core protein participates in HCV-related hepatocarcinogenesis, transgenic mouse lines were established in which HCV core protein is expressed constitutively in liver at cellular levels similar to those found in chronic HCV-infected patients (7). These mice exhibited hepatic steatosis (7) and insulin resistance (8) as early as 3 months of age; on further aging, these symptoms worsened and hepatic adenomas developed in approximately $30 \%$ of mice between 16 and 18 months of age (9). Finally, HCC was found within hepatic adenomas in a classic "nodule-in-nodule" pathology (9). Interestingly, no hepatic inflammation or fibrosis was found in these mice throughout

Nonstandard abbreviations used: ACC, acetyl-CoA carboxylase; AOX, acyl-CoA oxidase; CDK, cyclin-dependent kinase; CYP4A1, cytochrome P450 4A1; FAS, fatty acid synthase; FAT, fatty acid translocase; FATP, fatty acid transport protein; HCC, hepatocellular carcinoma; HCVcpTg, HCV core protein-expressing transgenic; L-FABP, liver fatty acid-binding protein; MCAD, medium-chain acyl-CoA dehydrogenase; MTP, microsomal transfer protein; 8-OHdG, 8-hydroxy-2'-deoxyguanosine; PCNA, proliferating cell nuclear antigen; $\mathrm{RXR} \alpha$, retinoid X receptor $\alpha$.

Conflict of interest: The authors have declared that no conflict of interest exists. Citation for this article: J. Clin. Invest. 118:683-694 (2008). doi:10.1172/JCI33594. the course of HCC development (9), which suggested that the $\mathrm{HCV}$ core protein itself induces hepatic steatosis and HCC independently of hepatitis.

Several studies support the contention that hepatic steatosis promotes the development of HCC (10). Epidemiologic data have identified hepatic steatosis as a major accelerating factor of hepatocarcinogenesis in chronic HCV-infected patients (11). Moreover, increases in ROS production that can cause oxidative DNA damage, mitochondrial abnormalities, and accelerated hepatocyte proliferation were observed in the steatotic livers (12-14). Thus, an intriguing possibility has emerged that alteration of fatty acid metabolism in hepatocytes may be central to the pathogenesis of HCC induced by HCV core protein.

PPARs are ligand-activated nuclear receptors belonging to the steroid/thyroid hormone receptor superfamily; 3 isoforms designated as $\alpha, \beta / \delta$, and $\gamma$ exist, all of which are involved in lipid homeostasis (15). PPAR $\alpha$ regulates constitutive transcription of genes encoding fatty acid-metabolizing enzymes (16) and is associated with the maintenance of fatty acid transport and metabolism, primarily in liver, kidney, and heart. Administration of PPAR $\alpha$ agonists, such as the widely prescribed fibrate drugs clofibrate, gemfibrozil, and fenofibrate, ameliorate hyperlipidemia in humans (17) and hepatic steatosis in mice (18).

On the other hand, long-term administration of PPAR $\alpha$ ligands to rodents causes accelerated hepatocyte proliferation, increased ROS generation, and development of $\operatorname{HCC}(19,20)$. Disruption of the PPAR $\alpha$ gene was shown to prevent the development of HCC caused by long-term exposure to PPAR $\alpha$ activators (21). Interestingly, accumulation of fatty acids/triglycerides in hepatocytes 
A
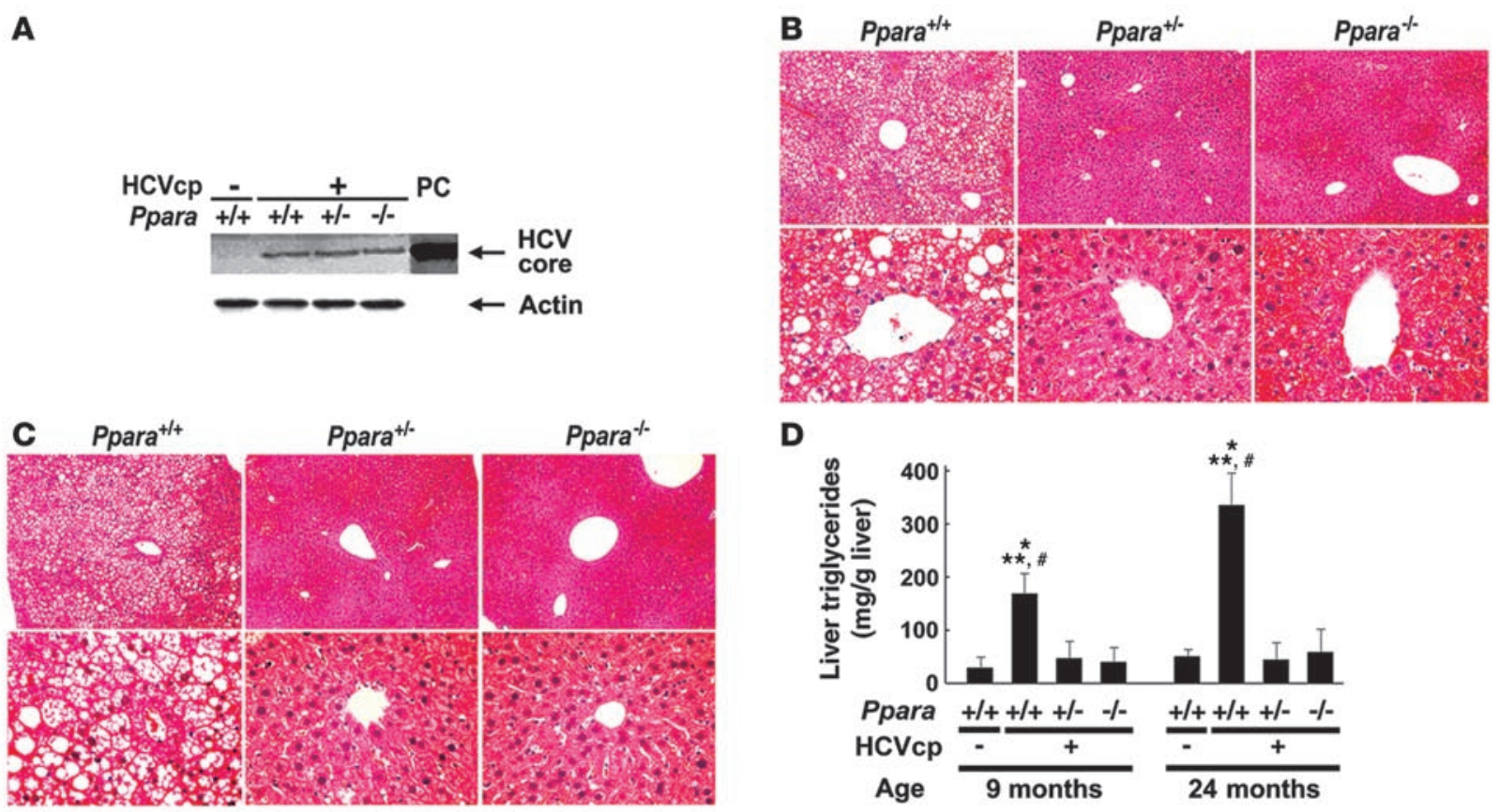

D

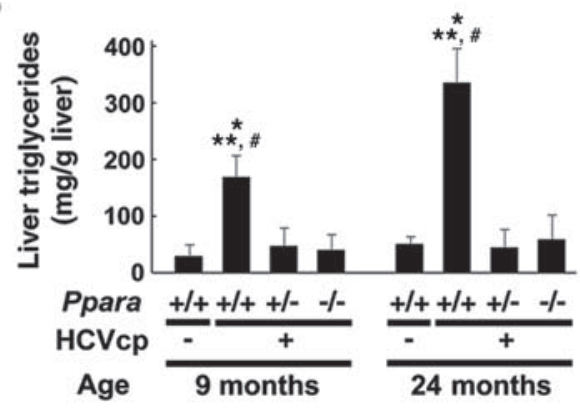

Figure 1

Phenotype changes in transgenic mouse liver. (A) Immunoblot analysis of HCV core protein expression in livers of 9-month-old mice. Because no significant individual differences in the same mouse group were found in the preliminary experiments, $10 \mathrm{mg}$ of liver prepared from each mouse ( $n=6 / \mathrm{group})$ was mixed and homogenized. Whole-liver lysate ( $50 \mu \mathrm{g}$ protein) was loaded in each well. The band of actin was used as the loading control. Results are representative of 4 independent experiments. PC, lysate prepared from COS-1 cells overexpressing HCV core protein as a positive control. (B) Histological appearance of hematoxylin- and eosin-stained liver sections from 9-month-old HCVcpTg mice. Upper and lower rows show a lower ( $\times 40$ ) and higher $(\times 400)$ magnification, respectively. Microvesicular and macrovesicular steatosis was found only in Ppara ${ }^{+/+}: \mathrm{HCV}_{\mathrm{cpTg}}$ mice. No inflammation or hepatocyte degeneration was evident in any of the genotypes. (C) Histological appearance of hematoxylin- and eosin-stained liver sections from 24-month-old HCVcpTg mice. Upper and lower rows show a lower $(\times 40)$ and higher $(\times 400)$ magnification, respectively. Hepatic steatosis was marked in Ppara ${ }^{+/+}:$HCV cpTg mice, but not in other mice. Hepatic inflammation, fibrosis, and hepatocyte degeneration were not observed. In Ppara ${ }^{+/-}$: $\mathrm{HCV}$ cpTg and $P$ para ${ }^{--}: \mathrm{HCV}$ cpTg mice, dysplastic hepatocytes and precancerous lesions were not detected throughout the entire liver. (D) Content of liver triglycerides. Results are expressed as the mean $\pm \mathrm{SD}\left(n=6 /\right.$ group) and compared between genotypes at the same age. ${ }^{*} P<0.05$ compared with $P$ para ${ }^{+/+}$nontransgenic mice; ${ }^{\star \star} P<0.05$ compared with $P$ para ${ }^{+/-}: \mathrm{HCV} c p T g$ mice; ${ }^{\#} P<0.05$ compared with $P$ para ${ }^{-/}: \mathrm{HCV}_{\mathrm{cpTg}}$ mice .

could lead to continuous PPAR $\alpha$ activation because of the presence of fatty acid metabolites that serve as natural PPAR $\alpha$ ligands. For example, mice lacking expression of the peroxisomal acyl-CoA oxidase (AOX) gene showed massive accumulation of very-longchain fatty acids in hepatocytes, severe microvesicular steatosis, chronic PPAR $\alpha$ activation, and development of hepatic adenoma and HCC by 15 months of age (22). These results suggest a strong contribution of activated PPAR $\alpha$ to liver tumorigenesis.

On the basis of several lines of evidence, we hypothesized that PPAR $\alpha$ might contribute to hepatocarcinogenesis in HCV core protein-expressing transgenic ( $\mathrm{HCV} c \mathrm{TTg}$ ) mice. To explore this possibility, PPAR $\alpha$-homozygous $\left(\mathrm{Ppara}^{+/+}\right)$, PPAR $\alpha$-heterozygous $\left(\mathrm{Ppara}^{+-}\right)$, and PPAR $\alpha$-null $\left(\right.$ Ppara $\left.^{-/}\right)$mice bearing the HCV core

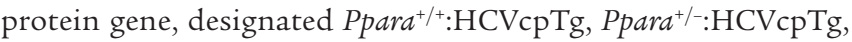
and $P$ para $^{-1-}:$ HCVcpTg mice, were generated, and phenotypic changes were examined. Surprisingly, we found that severe hepatic steatosis and HCC induced by HCV core protein developed only in $\mathrm{Ppara}^{+/+}$mice, which were related to persistent PPAR $\alpha$ activation.

\section{Results}

Expression of HCV core protein in transgenic mice. Ppara-1-:HCVcpTg and $\mathrm{Ppara}^{+/-} \mathrm{HCVcpTg}$ mice appeared healthy, and body weight in both genotypes was similar to that of $\mathrm{Ppara}^{+/+}: \mathrm{HCV} \mathrm{cpTg}$ and $\mathrm{Ppara}^{+/+}$mice without the transgene. When hepatic expression of HCV core protein in 9-month-old transgenic mice was examined by immunoblot analysis, it was similar among $\mathrm{Ppara}^{+/+}: \mathrm{HCVcpTg}, \mathrm{Ppara}^{+/-} \mathrm{HCVcpTg}$, and

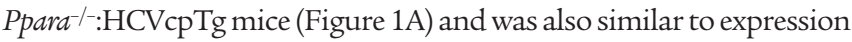
in HCVcpTg mice reported previously $(7,9)$. Age and sex had only a minor influence on the hepatic expression of HCV core protein.

Requirement of homozygous PPAR $\alpha$ for the development of hepatic steatosis in transgenic mice. Livers of 9-month-old male HCVcpTg mice with or without the Ppara allele were examined. Those of $\mathrm{Ppara}^{+/+}$: $\mathrm{HCV}$ cpTg mice were soft, slightly enlarged, and light in color and histologically showed macrovesicular and microvesicular steatosis with no apparent inflammation or hepatocyte necrosis (Figure 1B), in agreement with previous reports $(7,9)$. Biochemical analysis of liver extracts showed marked hepatic accumulation of triglycerides (Figure 1D). In contrast, livers of 9-month-old $\mathrm{Ppara}^{+/-} \mathrm{HCVcpTg}$ and Pparal-:HCVcpTg mice showed neither histological abnormalities nor accumulation of triglycerides (Figure 1, B and D). Hepatic levels of free fatty acids in $\mathrm{Ppara}^{+/+}$HCVcpTg mice were approximately 3 times those in Ppara ${ }^{+/-}: \mathrm{HCV} c \mathrm{~T}$ g and $\mathrm{Ppara}^{-/-} \mathrm{HCV} \mathrm{cpTg}$ mice or $\mathrm{Ppara}^{+/+}$mice not expressing the HCV core protein.

In 24-month-old $\mathrm{Ppara}^{+/+}: \mathrm{HCV}$ cpTg mice, hepatic steatosis was found (Figure 1C), and the hepatic levels of triglycerides were further increased (Figure 1D). Apparent inflammation, hepatocyte 
A

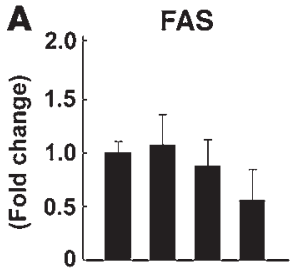

Ppara $+/++++++/--1-$

HCVcp $-\frac{+}{\text { FATP }}$

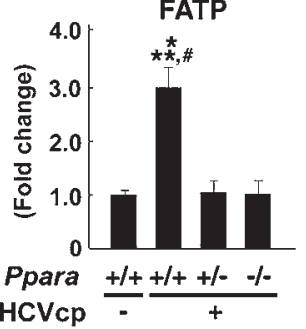

L-FABP
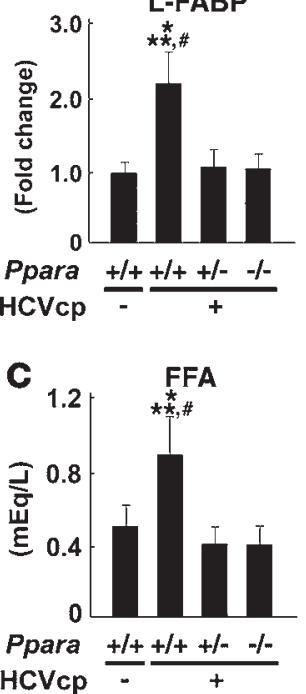
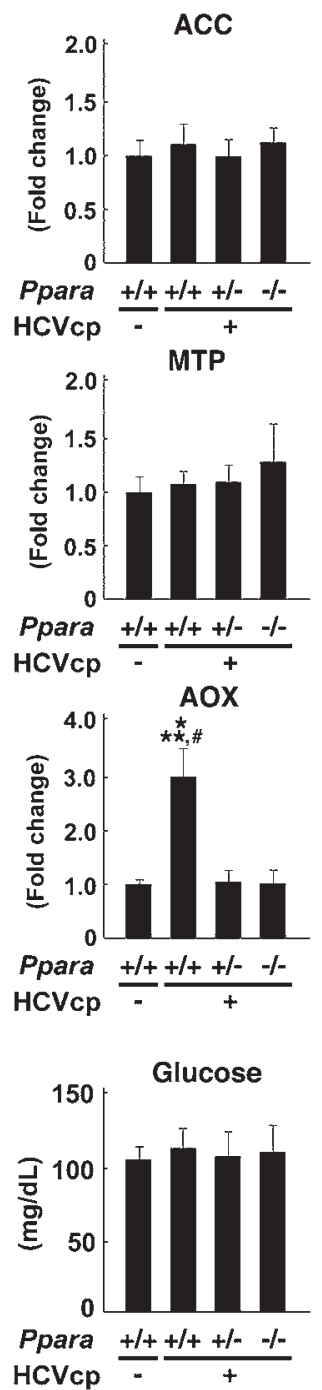
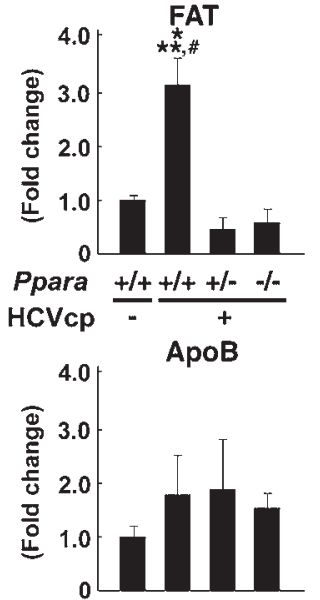

Ppara $\frac{+/+t+++/--t-}{+}$
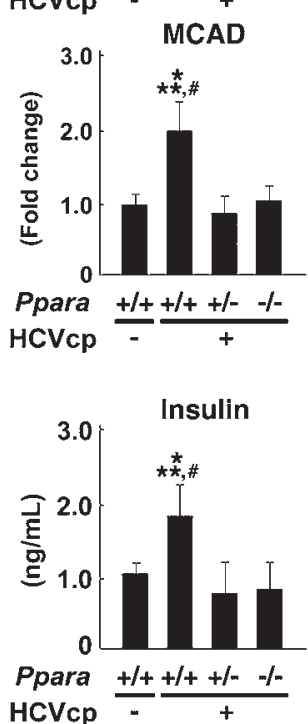

B

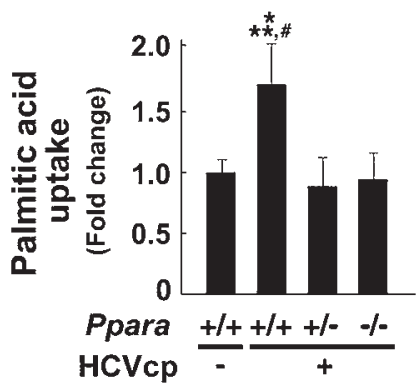

Figure 2

Analyses of factors associated with hepatic fatty acid and triglyceride metabolism. (A) Expression of genes associated with fatty acid and triglyceride metabolism in 9-month-old mouse livers. Total RNA was extracted from each mouse liver, and mRNA levels were determined by RT-PCR. mRNA levels were normalized by those of GAPDH and subsequently normalized by those in $P$ para ${ }^{+/+}$nontransgenic mice. Results are expressed as the mean $\pm \mathrm{SD}$ ( $n=6$ /group). ${ }^{\star} P<0.05$ compared with $P$ para ${ }^{+/+}$nontransgenic mice; ${ }^{* *} P<0.05$ compared with $P$ para ${ }^{+/-}:$HCVcpTg mice; ${ }^{\#} P<0.05$ compared with $P$ para ${ }^{-l-}$ :HCVcpTg mice. (B) Uptake of fatty acids in 9 -month-old mouse livers. Liver slices obtained from 3 mice in each group were incubated in medium containing $0.8 \mathrm{mM}\left[1-{ }^{14} \mathrm{C}\right]$ palmitic acid for $7 \mathrm{~h}$. Fatty acid uptake ability was estimated by the sum of palmitic acid converted to $\mathrm{CO}_{2}$ and ketone bodies with that incorporated into total cellular lipids after incubation. The experiment was repeated 3 times. Results were normalized by those of Ppara+/+ nontransgenic mice and expressed as the mean \pm SD. (C) Plasma concentrations of free fatty acids, glucose, and insulin. After an overnight fast, blood was obtained from each mouse and the above variables were determined. Results are expressed as the mean $\pm \mathrm{SD}(n=6 /$ group$)$.

degeneration and necrosis, and fibrosis were not detected. On the other hand, $P$ para ${ }^{+/}:$HCVcpTg and Ppara-/-:HCVcpTg mice showed no steatosis (Figure 1, C and D). These results indicate that hepatic steatosis develops in $\mathrm{Ppara}^{+/+}: \mathrm{HCV}$ cpTg mice, but not in Ppara ${ }^{+/-}$: $\mathrm{HCV} c \mathrm{Tg}$ and $P$ para ${ }^{-1}: \mathrm{HCV} \mathrm{cpTg}$ mice.

Hepatic fatty acid and triglyceride metabolism in transgenic mice. To investigate the mechanism responsible for the development of severe steatosis in $\mathrm{Ppara}^{+/+}: \mathrm{HCV} \mathrm{cpTg}$ mice, the expression of genes associated with fatty acid and triglyceride metabolism in the livers of 9-month-old mice was analyzed using the quantitative RT-PCR method. As shown in Figure 2A, the mRNA levels of genes related to de novo lipogenesis (fatty acid synthase [FAS] and acetyl-CoA carboxylase $[\mathrm{ACC}]$ ) and secretion of VLDL (microsomal transfer protein [MTP] and apoB) were constant in all groups. The mRNA levels of fatty acid translocase (FAT) and fatty acid transport protein (FATP), which are associated with the uptake of fatty acids into hepatocytes, were significantly increased only in $\mathrm{Ppara}^{+/+}: \mathrm{HCV} c \mathrm{PT}$ mice, but the mRNA levels of hepatic triglyceride lipase, another contributor to fatty acid uptake, remained unchanged (data not shown). The mRNA levels of liver fatty acid binding protein (L-FABP) were also elevated only in $\mathrm{Ppara}^{+/+}: \mathrm{HCV} \mathrm{cpTg}$ mice. Surprisingly, the mRNA levels of AOX and medium-chain acyl-CoA 
A

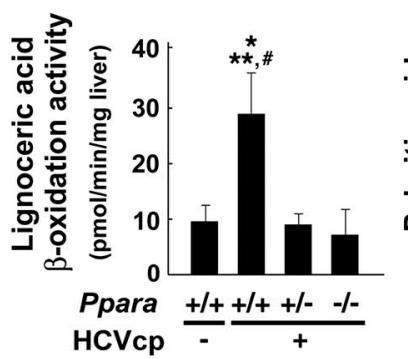

C

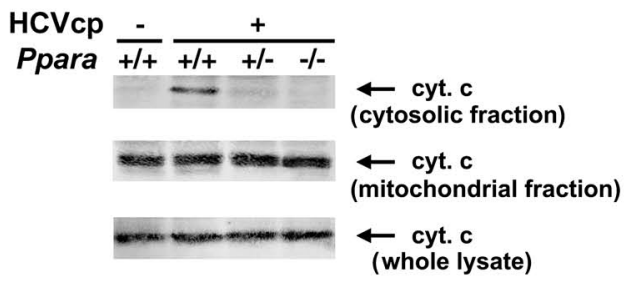

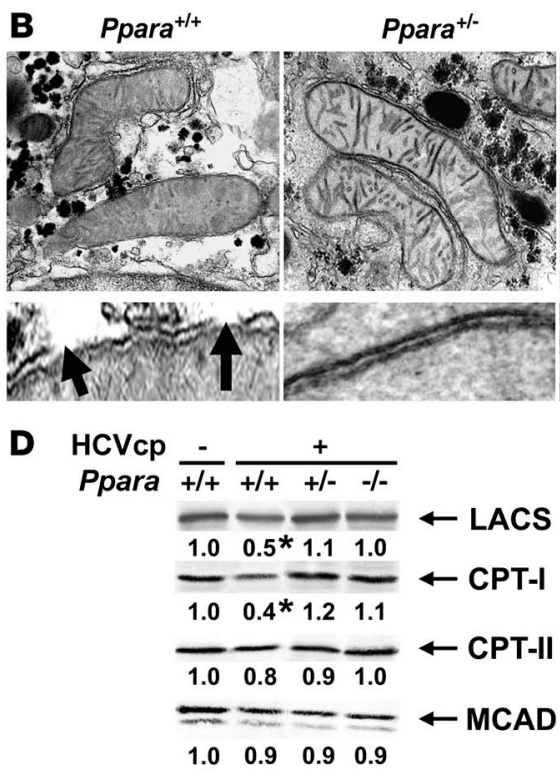

Figure 3

Analyses of mitochondrial abnormalities. (A) Lignoceric and palmitic acid $\beta$-oxidation activities in 9-month-old mice. Results are expressed as the mean $\pm \mathrm{SD}$ ( $n=6$ /group). ${ }^{*} P<0.05$ compared with $P$ para ${ }^{+/+}$nontransgenic mice; ${ }^{* *} P<0.05$ compared with $P$ para ${ }^{+-}: \mathrm{HCV}_{\mathrm{cpTg}}$ mice; ${ }^{\#} P<0.05$ compared with Ppara ${ }^{-/}:$HCVcpTg mice. (B) Electron microscopic features of hepatic mitochondria of 9-month-old HCVcpTg mice. Upper and lower rows show a lower and higher magnification, respectively. In Ppara ${ }^{+/+}: \mathrm{HCV} c p T g$ mice, some mitochondria showing discontinuance of outer membranes (arrows) and amorphous inner structures were observed. In Ppara ${ }^{+/}: \mathrm{HCV} c p T g$ and Ppara ${ }^{-/}: \mathrm{HCV}_{\mathrm{cpTg}}$ mice, mitochondria appeared normal; the scale bars represent $200 \mathrm{~nm}$ (top) and $30 \mathrm{~nm}$ (bottom), respectively. (C) Immunoblot analysis of cytochrome $c$ in 9-monthold mice. Whole-liver lysate, mitochondrial fraction, or cytosolic fraction (50 $\mu \mathrm{g}$ protein) was loaded in each well. Results are representative of 4 independent experiments. (D) Immunoblot analysis of representative mitochondrial $\beta$-oxidation enzymes using a mitochondrial fraction prepared from 9-month-old mouse livers. The mitochondrial fraction (20 $\mu \mathrm{g}$ protein) was loaded in each well. Results are representative of 4 independent experiments. The band intensity was quantified densitometrically and normalized by that in $P$ para ${ }^{+/+}$nontransgenic mouse. The mean value of the fold changes is shown under the representative band. LACS, long-chain acyl-CoA synthase; CPT, carnitine palmitoyl-CoA transferase.

dehydrogenase (MCAD), a rate-limiting enzymes in the peroxisomal and mitochondrial $\beta$-oxidation pathways, respectively, were significantly increased in $\mathrm{Ppara}^{+/+}: \mathrm{HCV}$ cpTg mice. When fatty acid uptake ability was measured in fresh liver slices, it was significantly enhanced only in $\mathrm{Ppara}^{+/+}: \mathrm{HCV} \mathrm{CpTg}$ mice (Figure 2B). Additionally, plasma free fatty acid levels were higher in these mice than in mice in the other groups. Although there were no differences in fasting plasma glucose levels between the groups, hyperinsulinemia was observed only in $\mathrm{Para}^{+/+}: \mathrm{HCVcpTg}$ mice (Figure 2C), in agreement with the previous observation that significant insulin resistance developed in these mice (8). Similar results were obtained from 24-month-old mice (data not shown). These results combined show that the increased plasma fatty acid levels, which were likely due to enhanced peripheral fatty acid release caused by insulin resistance, and the increase in fatty acid uptake ability are consistent with steatogenesis in $\mathrm{Ppara}^{+/+}: \mathrm{HCV}$ cpTg mice.

Decreased mitochondrial $\beta$-oxidation in transgenic mice. Although the transcriptional activities of major $\beta$-oxidation enzymes were markedly increased, $\mathrm{Ppara}^{+/+}: \mathrm{HCV} \mathrm{cpTg}$ mice had severe steatosis. To explore this discrepant result, peroxisomal and mitochondrial $\beta$-oxidation activities were measured using lignoceric and palmitic acids as substrates, respectively. The lignoceric acid-degrading capacity was increased only in $\mathrm{Ppara}^{+/+}: \mathrm{HCV} c \mathrm{~T}$ g mice, where it corresponded to an increase in AOX expression. However, the capacity for palmitic acid degradation, which occurs particularly in mitochondria, was significantly lower in $\mathrm{Ppara}^{+/+}: \mathrm{HCV} c \mathrm{Tg}$ mice than in Para $^{+/-}: \mathrm{HCV}_{\mathrm{cpTg}}$ and Ppara- ${ }^{--}: \mathrm{HCV}$ cpTg mice (Figure 3A).
Thus, decreased mitochondrial $\beta$-oxidation ability was considered to be another important mechanism for the development of steatosis induced by the core protein.

We further evaluated mitochondrial abnormalities. In electron microscopic examination, discontinuous outer membranes (Figure $3 \mathrm{~B}$, arrows) and lack of an internal structure were observed in some mitochondria of $\mathrm{Ppara}^{+/+}: \mathrm{HCV} \mathrm{cpTg}$ mouse livers, in agreement with the previous report (9). However, these abnormalities were not seen in Ppara ${ }^{+/-}:$HCVcpTg and Ppara $/-: H C V c p T g$ mice (Figure 3B). Immunoblot analysis showed that cytochrome $c$, which is usually localized in the mitochondrial intermembrane space, was present in the cytosolic fractions of Ppara ${ }^{+/}: \mathrm{HCV}$ cpTg mice (Figure 3C). Moreover, immunoblot analysis using mitochondrial fractions showed that the expression levels of long-chain acyl-CoA synthase and carnitine palmitoyl-CoA transferase-I, which are enzymes indispensable to the initial step of mitochondrial $\beta$-oxidation and are localized mainly in mitochondrial outer membranes, were significantly decreased only in $\mathrm{Ppara}^{+/+}: \mathrm{HCV} c \mathrm{TT}$ mice (Figure 3D).

Overall, these results suggest that homozygous PPAR $\alpha$ is essential to the pathogenesis of hepatic steatosis induced by the HCV core protein, which results from a decrease in mitochondrial fatty acid degradation capacity caused by the breakdown of mitochondrial outer membranes and a disproportionate increase in the uptake of fatty acids. Interestingly, steatosis and the related changes did not occur in $\mathrm{Ppara}^{+/-}$and $\mathrm{Ppara}^{-/-}$mice expressing the $\mathrm{HCV}$ core protein, which suggested that these changes were not caused by the core protein itself. 
Table 1

Incidence of HCC in 24-month-old mice

$\begin{array}{lcccc}\text { HCV core protein } & \text { Ppara } & \begin{array}{c}\text { Mice } \\ (\boldsymbol{n})\end{array} & \begin{array}{c}\text { Mice with HCC } \\ (\boldsymbol{n})\end{array} & \begin{array}{c}\text { Incidence } \\ (\%)\end{array} \\ - & & 20 & 0 & 0 \\ - & +/+ & 20 & 0 & 0 \\ - & +- & 18 & 0 & 0 \\ + & -/- & 20 & 6 & 35.3^{\mathrm{A}} \\ + & +/+ & 17 & 0 & 0 \\ + & +/- & 16 & 0 & 0\end{array}$

Mice were killed at 24 months of age for analysis. HCC was diagnosed according to histological findings. AP $<0.05$ compared with $P$ para ${ }^{+/+}$ nontransgenic mice, $P<0.05$ compared with $P$ para ${ }^{+/}: \mathrm{HCV}$ cpTg mice, $P<0.05$ compared with Ppara ${ }^{-1}: \mathrm{HCV}$ cpTg mice.

Requirement of homozygous PPAR $\alpha$ for hepatic tumor development in transgenic mice. At 9 months of age, hepatic nodules were not observed at all in transgenic mice, whereas, at 24 months, approximately $35 \%$ of $\mathrm{Ppara}^{+/+}: \mathrm{HCV} \mathrm{cpTg}$ mice had macroscopically evident hepatic nodules (Table 1). Microscopically, these nodules had the appearance of well-differentiated HCC with trabecular features, which was consistent with the previous report (9). Surprisingly, $\mathrm{Para}^{+/-}: \mathrm{HCV} \mathrm{cpTg}$ and $\mathrm{Ppara}^{-/}: \mathrm{HCV} \mathrm{cpTg}$ mice of the same ages developed no evidence of hepatic tumors, despite the expression of $\mathrm{HCV}$ core protein at similar levels to those found in Ppara ${ }^{+/+}: H C V c p T g$ mice (Table 1). Microscopic examination showed that there were no dysplastic cells or precancerous lesions throughout the livers in $\mathrm{Ppara}^{+/-}: \mathrm{HCV} \mathrm{cpTg}$ and Ppara $^{-1-}:$ HCVcpTg mice (Figure 1C). These results provide strong evidence that homozygous PPAR $\alpha$ is essential for hepatic tumorigenesis induced by HCV core protein.

Increased hepatocyte proliferation only in $\mathrm{Ppara}^{+/+}: \mathrm{HCV} c \mathrm{Tg}$ mice. Because sustained acceleration of hepatocyte proliferation relative to apoptosis may promote the development of HCC, these opposing processes were quantified in the livers of 24-monthold mice. Both the liver-to-body weight ratio and the number of hepatocytes expressing proliferating cell nuclear antigen (PCNA) were increased only in $\mathrm{Ppara}^{+/+}: \mathrm{HCV}$ cpTg mice (Figure 4, A and B). In contrast, the number of TUNEL-positive hepatocytes and the hepatic caspase 3 activity, indicators of hepatocyte apoptosis, remained similar among the 3 mouse strains (Figure 4, C and D). Interestingly, despite the presence of $\mathrm{HCV}$ core protein, the amounts of these proliferative and apoptotic markers in $\mathrm{Ppara}^{+/-}$: HCVcpTg and Ppara-l-:HCVcpTg mice were similar to those in $\mathrm{Ppara}^{+/+}$nontransgenic mice. Expression levels of several proteins, such as protooncogenes (c-Fos and c-Myc), cell-cycle regulators (cyclin D1, cyclin-dependent kinase [CDK] 4, and PCNA), and phosphorylated ERK 1 and 2, all of which are associated with hepatocyte proliferation, were elevated in $\mathrm{Ppara}^{+/+}: \mathrm{HCV} c \mathrm{PTg}$ mice but not in other genotypes (Figure 4, E and F).

Increased oxidative stress and DNA damage only in $\mathrm{Ppara}^{+/+}: \mathrm{HCVcpTg}$ mice. $\mathrm{HCV}$ core protein is associated with increased production of ROS (23). Enhanced ROS production induces nuclear DNA damage, which results in the initiation of hepatocarcinogenesis, and can also injure organelles, which can result in disorders in their
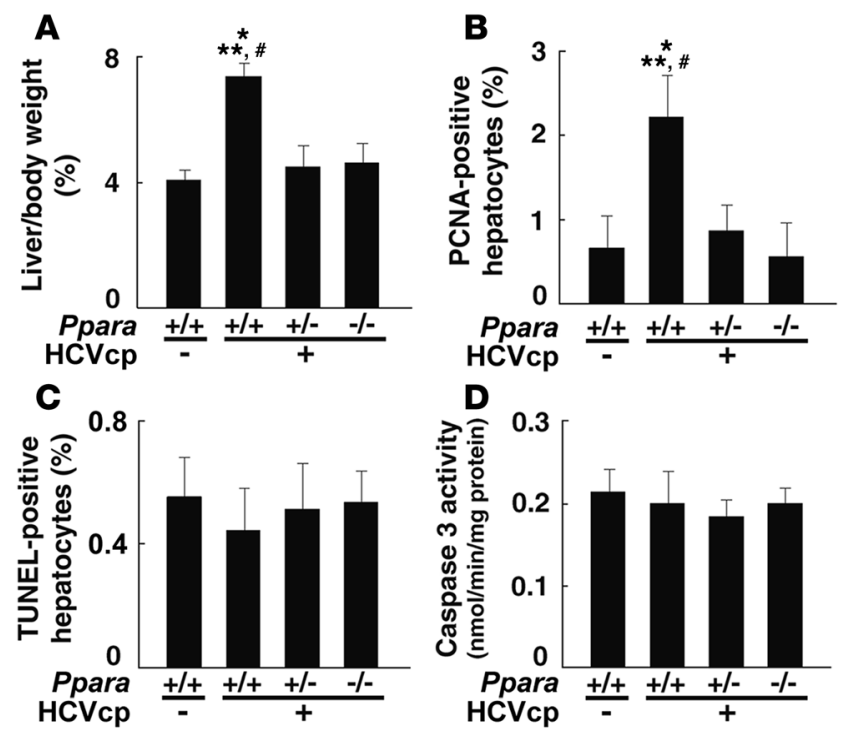
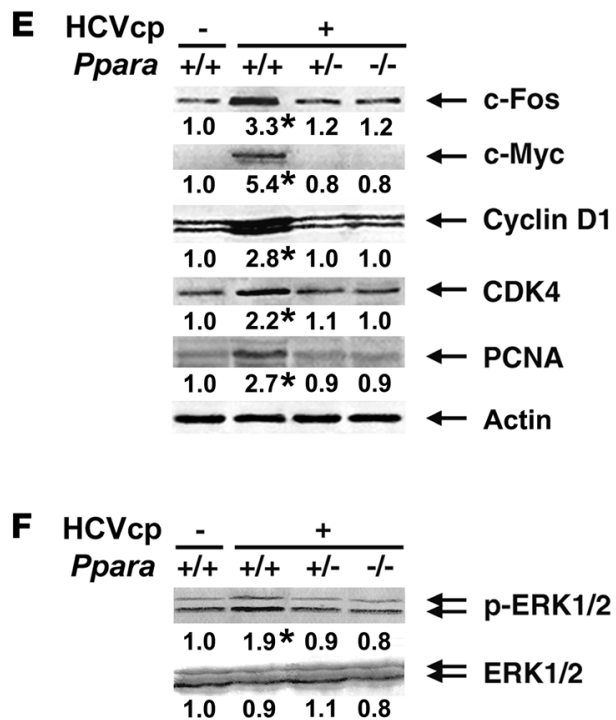

Figure 4

Increased hepatocyte proliferation in Ppara ${ }^{+/+}: \mathrm{HCV}_{\mathrm{c} T g}$ mice at 24 months of age. (A) Liver-to-body-weight ratio. Results are expressed as the mean \pm SD ( $n=6$ /group). (B) Numbers of proliferating hepatocytes. Two thousand hepatocytes were examined in each mouse, and hepatocyte nuclei positive for anti-PCNA antibody were counted. Results are expressed as the mean \pm SD ( $n=6 / g r o u p)$. For $\mathbf{A}$ and $\mathbf{B}$, comparisons are designated as follows: ${ }^{*} P<0.05$ compared with $P$ para ${ }^{+/+}$nontransgenic mice; ${ }^{* *} P<0.05$ compared with $P p a r a^{+/-}: \mathrm{HCV}_{\mathrm{cpTg}}$ mice; ${ }^{\#} P<0.05$ compared with Ppara-l-:HCVcpTg mice. (C) Numbers of apoptotic hepatocytes. Liver sections were subjected to TUNEL staining, and TUNELpositive hepatocyte nuclei were counted in 2,000 hepatocytes from each mouse. Results are expressed as the mean \pm SD ( $n=6 / g r o u p)$. (D) Caspase 3 activity. Results are expressed as the mean \pm SD $(n=6 / g r o u p)$. (E) Immunoblot analysis of oncogene products and cell cycle regulators. The same sample used in Figure 1A (whole-liver lysate, $50 \mu \mathrm{g}$ protein) was loaded in each well. The band of actin was used as the loading control. Results are representative of 4 independent experiments. The band intensity was quantified densitometrically, normalized by that of actin, and subsequently normalized by that in $\mathrm{Ppara}^{+/+}$nontransgenic mice. The mean value of the fold changes is expressed under each band. (F) Immunoblot analysis of phosphorylated ERK1/2 and total ERK1/2. The same samples in Figure 4E (50 $\mu$ g protein) were used. 


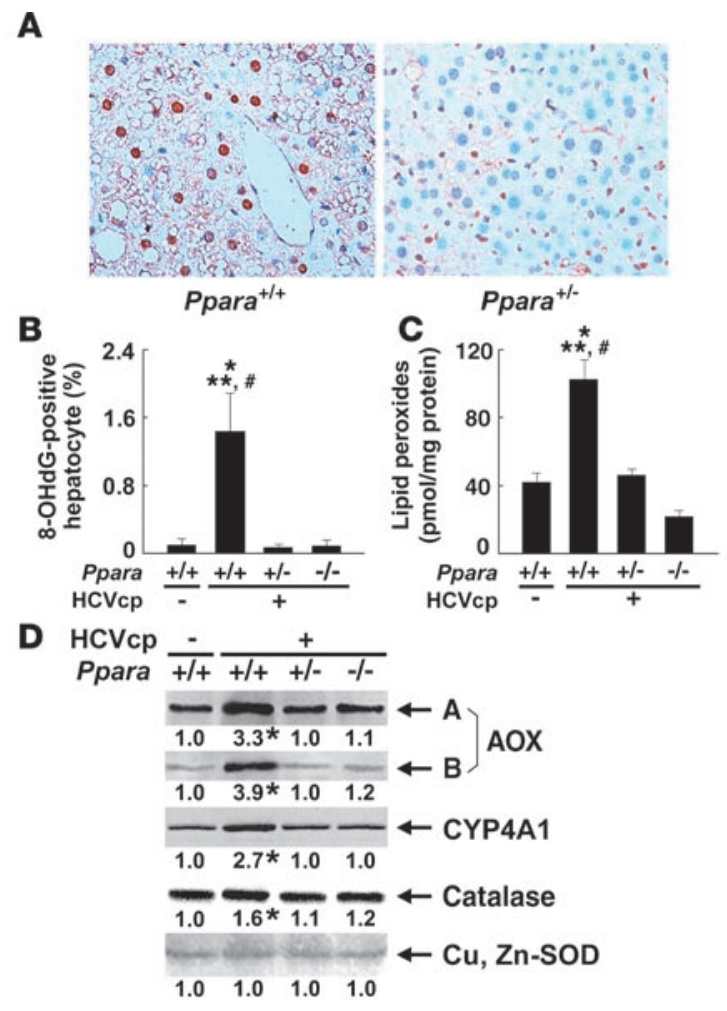

function. The number of hepatocytes positive for 8-hydroxy-2'deoxyguanosine (8-OHdG), an indicator of oxidative damage to nuclear DNA, was increased only in 24-month-old $\mathrm{Ppara}^{+/+}$: HCVcpTg mice (Figure 5, A and B). Lipid peroxides were slightly increased in the livers of 9-month-old $\mathrm{Ppara}^{+/+}: \mathrm{HCV} c \mathrm{Tg}$ mice (data not shown) and were more abundant in the livers of 24-monthold $\mathrm{Ppara}^{+/+}: \mathrm{HCV}$ cpTg mice than in those of $\mathrm{Ppara}^{+/-}: \mathrm{HCV} \mathrm{cpTg}$ and $\mathrm{Ppara}^{-/-}: \mathrm{HCV} \mathrm{CpTg}$ mice or $\mathrm{Ppara}^{+/+}$nontransgenic mice (Figure 5C). Expression of typical ROS-generating enzymes (AOX and cytochrome P450 4A1 [CYP4A1]) and ROS-eliminating enzymes (catalase and $\mathrm{Cu}, \mathrm{Zn}$-SOD) was examined. Immunoblot analysis showed marked increases in the expression of AOX and CYP4A1 and mild increases in that of catalase only in $\mathrm{Ppara}^{+/+}: \mathrm{HCV} \mathrm{cpTg}$ mice. No changes in $\mathrm{Cu}, \mathrm{Zn}$-SOD were found in the subgroups of transgenic mice (Figure 5D). These results suggest that enhanced oxidative stress causes damage in nuclear DNA and probably in mitochondria in the $\mathrm{Ppara}^{+/+}: \mathrm{HCV} \mathrm{cpTg}$ mice.

Persistent and spontaneous PPAR $\alpha$ activation in $\mathrm{Ppara}^{+/+}: \mathrm{HCV} c \mathrm{Tg}$ mice. Liver tumorigenesis induced by long-term exposure to peroxisome proliferators and the related changes, such as sustained hepatocyte proliferation and increased oxidative stress, are associated with persistent PPAR $\alpha$ activation (19-21). To examine the activation of PPAR $\alpha$, we quantified the level of PPAR $\alpha$ mRNA, which is induced by PPAR $\alpha$ activation $(24,25)$. PPAR $\alpha$ mRNA levels were higher in 9-month-old $\mathrm{Ppara}^{+/+}: \mathrm{HCV}$ cpTg mice than in $\mathrm{Ppara}^{+/+}$nontransgenic mice (Figure 6A). These increases were more pronounced at 24 months of age. However, there were no differences in PPAR $\alpha$ mRNA levels between $\mathrm{Ppara}^{+/-}: \mathrm{HCV} \mathrm{cpTg}$ and $\mathrm{Ppara}^{+/-}$nontransgenic mice at either 9 or 24 months of age. The expression levels of typical PPAR $\alpha$ target genes $(16,25,26)$ - such as FAT, FATP, L-FABP, AOX, and MCAD (Figure 2); c-Myc, cyclin D1, CDK4, and PCNA (Figure 4); and CYP4A1 (Figure 5)

\section{Figure 5}

Increased oxidative stress and DNA damage in Ppara ${ }^{+/+}: \mathrm{HCV} c p T g$ mice at 24 months of age. (A) Immunohistochemical staining using antibody against $8-O H d G$. In Ppara ${ }^{+/+}: H C V c p T g$ mice, some steatotic hepatocytes were positive for $8-\mathrm{OHdG}$. Original magnification, $\times 400$. (B) Numbers of 8-OHdG-positive hepatocytes. Hepatocyte nuclei stained with anti-8-OHdG antibody were counted in 2,000 hepatocytes of each mouse. Results are expressed as the mean \pm SD ( $n=6 /$ group). (C) Hepatic content of lipid peroxides. Results are expressed as the mean \pm SD ( $n=6$ /group). ${ }^{*} P<0.05$ compared with $P$ para ${ }^{+/+}$nontransgenic mice; ${ }^{* *} P<0.05$ compared with $P$ para ${ }^{+/-}$: HCVcpTg mice; ${ }^{\#} P<0.05$ compared with $P$ para ${ }^{-1}:$ HCVcpTg mice. (D) Immunoblot analysis of AOX, CYP4A1, catalase, and Cu, Zn-SOD. The whole-liver lysate used in the experiment in Figure 4E $(20 \mu \mathrm{g}$ protein for AOX and CYP4A1 and $50 \mu \mathrm{g}$ for others) was loaded in each lane. The band of actin was used as the loading control. Results are representative of 4 independent experiments. A and B indicate full-length and truncated AOX, respectively. The band intensity was quantified densitometrically, normalized by that of actin, and subsequently normalized by that in $\mathrm{Ppara}^{+/+}$nontransgenic mice. The mean value of the fold changes is expressed under each band. ${ }^{*} P<0.05$ compared with $\mathrm{Ppara}^{+/+}$nontransgenic mice.

- were simultaneously and synchronously increased in $\mathrm{Ppara}^{+/+}$: HCVcpTg mice, but not in Ppara+/-:HCVcpTg or Ppara-/-:HCVcpTg mice. These results confirm that persistent activation of PPAR $\alpha$ occurs only in $\mathrm{Ppara}^{+/+}: \mathrm{HCV} \mathrm{cpTg}$ mice. Various changes observed in $\mathrm{Ppara}^{+/+}: \mathrm{HCV} \mathrm{cpTg}$ mice, i.e., increased fatty acid uptake, mitochondrial abnormalities, steatosis, ROS overproduction, accelerated hepatocyte proliferation, and hepatocarcinogenesis, were considered to be closely linked with sustained PPAR $\alpha$ activation.

Nuclear PPAR $\alpha$ content. The results described above suggest that persistent PPAR $\alpha$ activation is critical to the steatogenesis and hepatocarcinogenesis induced by the HCV core protein. A question arises as to why $P$ para ${ }^{+}-:$HCVcpTg mice with an active Ppara allele do not exhibit the hallmarks of PPAR $\alpha$ activation and do not develop HCC. To address this issue, the nuclear PPAR $\alpha$ content was analyzed. Immunoblot analysis for PPAR $\alpha$ showed that the amount of nuclear PPAR $\alpha$ protein in $\mathrm{Ppara}^{+/+}: \mathrm{HCV} \mathrm{cpTg}$ mice was approximately 2 - to 3-fold that of $\mathrm{Ppara}^{+/+}$nontransgenic mice, which was disproportionate to the higher PPAR $\alpha$ mRNA levels (approximately 1.2- to 1.6-fold) (Figure 6, A and B). The level of nuclear PPAR $\alpha$ in $\mathrm{Ppara}^{+/-}: \mathrm{HCV}$ cpTg mice was significantly lower than that in $\mathrm{Ppara}^{++}: \mathrm{HCV}$ cpTg mice and was similar to that in $\mathrm{Ppara}^{+/+}$nontransgenic mice (Figure 6B). Thus, the lower amount of nuclear PPAR $\alpha$ in $\mathrm{Ppara}^{+/}:$HCVcpTg mice than in $\mathrm{Ppara}^{+/+}$: $\mathrm{HCV} c \mathrm{~T} T \mathrm{~g}$ mice might have heightened the threshold of expression required for long-term spontaneous PPAR $\alpha$ activation.

The degree of an increase in nuclear PPAR $\alpha$ levels was evidently higher than the degree of an increase in PPAR $\alpha$ mRNA levels in HCVcpTg mice (Figure 6, A and B). To investigate this disparity, the stability of nuclear PPAR $\alpha$ was evaluated by pulse-chase experiments using isolated hepatocytes obtained from these mice. The half-life of nuclear PPAR $\alpha$ was significantly longer $(P<0.05)$ in $\mathrm{Ppara}^{+/+}: \mathrm{HCV}$ cpTg mice $(11.5 \pm 2.3 \mathrm{~h})$ than in $\mathrm{Ppara}^{+/+}$nontransgenic mice $(5.8 \pm 1.4 \mathrm{~h}$ ) (Figure $6 \mathrm{C})$. The half-life of nuclear PPAR $\alpha$ in $\mathrm{Ppara}^{+/-}: \mathrm{HCV} \mathrm{cpTg}$ mice tended to be prolonged compared with that in $\mathrm{Ppara}^{+/-}$nontransgenic mice (Figure 6C). These results suggest that the stability of nuclear PPAR $\alpha$ was increased as a result of $\mathrm{HCV}$ core protein expression. Because it is known that the core protein interacts with retinoid X receptor $\alpha(\operatorname{RXR} \alpha)(27)$ and that 
A

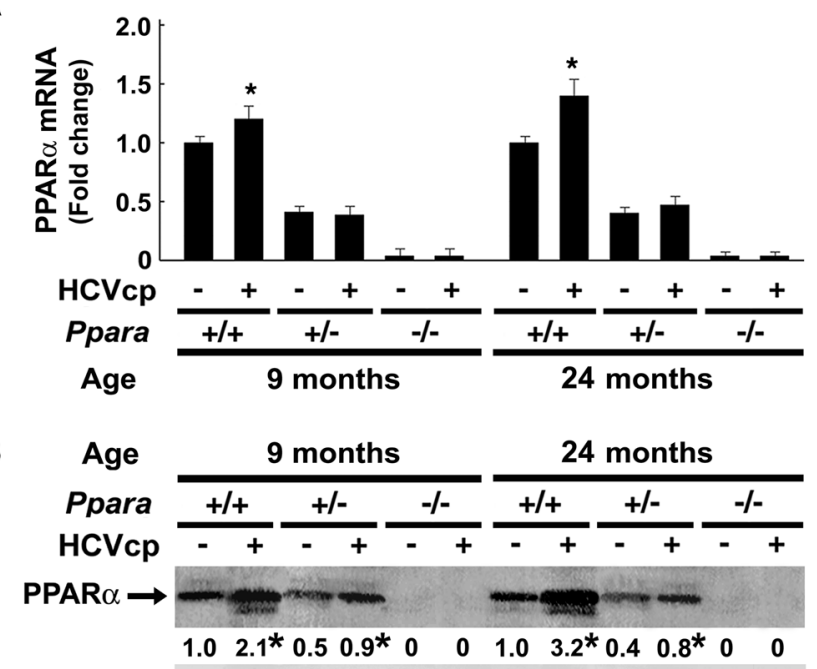

Histone $\mathrm{H} 1 \rightarrow$

C

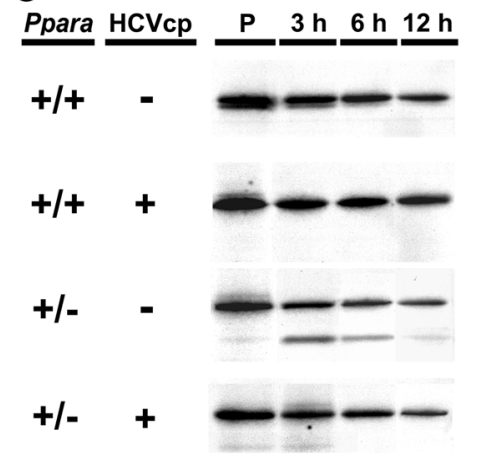

\section{Figure 6}

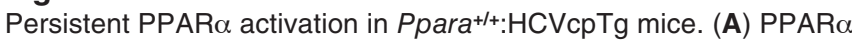
mRNA levels. Total RNA was prepared from each mouse, and PPAR $\alpha$ mRNA levels were determined by RT-PCR, normalized by those of GAPDH, and subsequently normalized by those of 9-month-old Ppara $^{+/+}$nontransgenic mice. Results are expressed as the mean \pm SD ( $n=6$ /group). (B) Immunoblot analysis of nuclear PPAR $\alpha$. The nuclear fraction obtained from each mouse (100 $\mu$ g protein) was loaded in each well. The band of histone $\mathrm{H} 1$ was used as the loading control. Results are representative of 6 independent experiments. The band intensity was quantified densitometrically, normalized by that of histone $\mathrm{H} 1$, and subsequently normalized by that in 9-month-old Ppara ${ }^{+/+}$ nontransgenic mice. The mean value is expressed under each band. ${ }^{*} P<0.05$ compared with nontransgenic mice of the same age and Ppara genotype. (C) Pulse-chase experiments for 3, 6, and $12 \mathrm{~h}$ and pulse-label $(P)$ experiments for nuclear PPAR $\alpha$ using isolated mouse hepatocytes. Left: labeled PPAR $\alpha$ bands on x-ray film. Pulse-label and pulse-chase experiments were performed as described in Methods. Results are representative of 4 independent experiments. Right: halflife of PPAR $\alpha$. The band intensity was measured densitometrically and subsequently normalized by that of the pulse-label experiments. The percentage of the band intensity was plotted, and the half-life of PPAR $\alpha$ was calculated. Results obtained from 4 independent experiments are expressed as the mean \pm SD. ${ }^{*} P<0.05$ compared with nontransgenic mice in the same Ppara genotype.
PPAR $\alpha$ influences the stability of $\operatorname{RXR} \alpha$ (28), it is plausible that the core protein would affect its action in nuclei through an interaction with the PPAR $\alpha$-RXR $\alpha$ heterodimer and stabilization of PPAR $\alpha$.

Development of hepatic steatosis and HCC with long-term clofibrate treatment in Ppara ${ }^{+/-}: H C V c p T g$ mice. To further confirm the significance of persistent PPAR $\alpha$ activation on core protein-induced pathological changes, $\mathrm{Ppara}^{+/-}$and $\mathrm{Ppara}^{+/-}: \mathrm{HCV} \mathrm{cpTg}$ mice were fed a standard diet containing $0.05 \%$ clofibrate for 24 months. Interestingly, hepatic steatosis appeared in the clofibrate-treated $\mathrm{Ppara}^{+/-}$: HCVcpTg mice, but not in the Ppara ${ }^{+/-}$mice under the same treatment conditions (Figure 7, A and B). Similar to our observations in $\mathrm{Ppara}^{+/+}: \mathrm{HCV}$ cpTg mice not treated with clofibrate, aberrant mitochondria with discontinuous outer membranes and decreased palmitic acid $\beta$-oxidation activity were found only in the clofibratetreated $\mathrm{Ppara}^{+/-}: \mathrm{HCV} \mathrm{cpTg}$ mice (Figure 7, A and C). In addition, levels of MCAD mRNA; AOX, and CYP4A1 proteins; PPAR $\alpha$ mRNA; and nuclear PPAR $\alpha$ protein were higher in the clofibrate-treated $\mathrm{Ppara}^{+/-}: \mathrm{HCV} \mathrm{cpTg}$ mice than in the clofibrate-treated $\mathrm{Ppara}^{+/-}$mice (Figure 7, D-F), which suggests that the degree of PPAR $\alpha$ activation in the former group was greater than that in the latter group and similar to that in $\mathrm{Ppara}^{+/+}: \mathrm{HCV}$ cpTg mice not treated with clofibrate. Finally, the incidence of HCC after clofibrate treatment was higher in Ppara ${ }^{+/}:$HCVcpTg mice (25\%; 5 in 20 mice) than in $\mathrm{Ppara}^{+-}$mice (5\%; 1 in 20 mice). Therefore, these results corroborate the importance of constant PPAR $\alpha$ activation to the pathogenesis of hepatic steatosis and HCC in the transgenic mice.

\section{Discussion}

A novel and striking finding in this study is the absolute requirement of persistent PPAR $\alpha$ activation for the development of $\mathrm{HCV}$ core protein-induced steatosis and HCC. Our data also show that the $\mathrm{HCV}$ core protein alone cannot induce steatosis and HCC in transgenic mice.

Mechanisms of development of steatosis in HCVcpTg mice were previously explained as an enhancement of de novo synthesis of fatty acids (29) and a decrease in MTP expression, the latter of which results in insufficient VLDL secretion from hepatocytes (30). In the present study, we revealed 2 novel mechanisms of steatogenesis in the transgenic mice, i.e., an impairment of mitochondrial $\beta$-oxidation due to the breakdown of mitochondrial outer membranes and an increase in fatty acid uptake into hepatocytes, associated with PPAR $\alpha$ activation. PPAR $\alpha$ activation, mitochondrial dysfunction, and hepatic steatosis appeared in 9-month-old $\mathrm{Ppara}^{+/+}: \mathrm{HCV} c \mathrm{Tg}$ mice and continued until 24 months of age, clearly preceding development of HCC. These findings thereby indicate a correlation between PPAR $\alpha$ activation, hepatic steatosis, and HCC.

We obtained the novel and rather paradoxical finding that significant PPAR $\alpha$ activation, which generally is expected to reduce hepatic triglyceride levels, is essential for the development of severe steatosis induced by HCV core protein. According to the results of this study, the following hypothesis concerning the development of steatosis in $\mathrm{Ppara}^{+/+}: \mathrm{HCV} \mathrm{cpTg}$ mice is proposed. First, the HCV core protein localizes partly in mitochondria (9). A recent study 

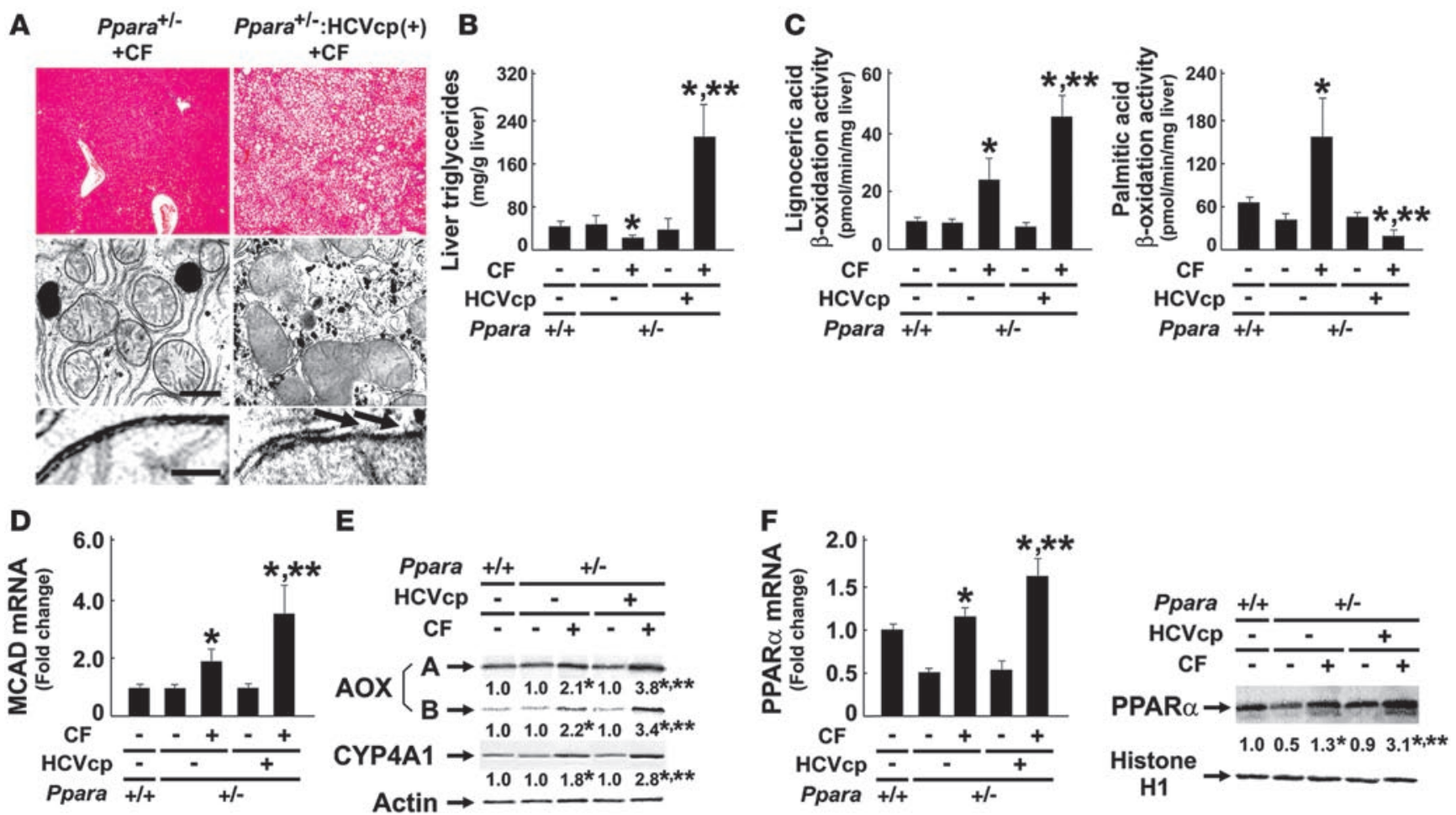

Figure 7

Development of hepatic steatosis by long-term treatment of clofibrate in Ppara ${ }^{+-}: \mathrm{HCV}_{\mathrm{cpTg}}$ mice. (A) Histological examination of $P$ para ${ }^{+/-}$and $P_{\text {para }}{ }^{+/-}: \mathrm{HCV} c p T g$ mice treated with diet containing $0.05 \%$ (w/w) clofibrate for 24 months (CF). Top: Histological appearance of H\&E-stained liver sections. Magnification, $\times 40$. Microvesicular and macrovesicular steatosis were detected only in clofibrate-treated $P$ para ${ }^{+/-}: \mathrm{HCV}_{\mathrm{cPT}} \mathrm{mice}$. Middle and bottom: Electron microscopic features of hepatic mitochondria. Some C-shaped mitochondria showing discontinuance of outer membranes (arrows) were found in clofibrate-treated Ppara ${ }^{+/-}$:HCV cpTg mice. Scale bars: $400 \mathrm{~nm}$ (middle), $30 \mathrm{~nm}$ (bottom). (B and C) Content of liver triglycerides and lignoceric and palmitic acid $\beta$-oxidation activities. (D) MCAD mRNA levels. mRNA levels were normalized to those of GAPDH and subsequently normalized to those in Ppara+/+ nontransgenic mice. (E) Immunoblot analysis of AOX and CYP4A1. Whole-liver lysate (20 $\mu \mathrm{g}$ protein) was loaded in each lane. Actin was used as a loading control. Results are representative of 6 independent experiments. (F) PPAR $\alpha$ mRNA levels and nuclear PPAR $\alpha$ contents. Left: PPAR $\alpha$ mRNA levels. The same samples used in $\mathbf{D}$ were adopted. Right: Immunoblot analysis of nuclear PPAR $\alpha$. Nuclear fraction obtained from each mouse (100 $\mu \mathrm{g}$ protein) was loaded in each well. Histone $\mathrm{H} 1 \mathrm{was}$ used as a loading control. In $\mathbf{E}$ and $\mathbf{F}$, the mean value of the fold changes is shown under each band. Results are representative of 6 independent experiments. Band intensity was quantified densitometrically, normalized to that of the loading control, and subsequently normalized to that in $P p a r a^{+/+}$ nontransgenic mice. ${ }^{*} P<0.05$ compared with untreated mice of the same genotype; ${ }^{* *} P<0.05$ compared with clofibrate-treated $P p a r{ }^{+/-}$mice without core protein gene. Results are expressed as mean \pm SD $(n=6 /$ group$)$.

showed that, in isolated mitochondria, the core protein directly increased $\mathrm{Ca}^{2+}$ influx, inhibited electron transport complex I activity, and induced ROS production (31), all of which can increase the fragility of mitochondria and depress mitochondrial function. In addition, the HCV core protein also localizes in nuclei (9) and can coexist in PPAR $\alpha$-RXR $\alpha$ heterodimer through a direct interaction with the DNA-binding domain of RXR $\alpha$, which enhances the transcriptional activity of PPAR $\alpha$ target genes, such as AOX, despite the absence of PPAR $\alpha$ ligands in cultured cells (27). The HCV core protein can also be involved in the PPAR $\alpha$-RXR $\alpha$ complex through a direct interaction with cyclic-AMP responsive element binding protein-binding protein (32), which is able to bind to PPAR $\alpha$ (33). Thus, the core protein probably serves as a coactivator and stabilizer of PPAR $\alpha$ in vivo, which was further confirmed in this study. Moreover, because it is also known that the core protein itself activates ERK1/2 and p 38 mitogen-activated protein kinase (34), these activations might phosphorylate PPAR $\alpha$ and thereby transactivate it (35). The core protein-induced PPAR $\alpha$ activation enhances the basal expression of AOX and CYP4A1, which leads to increased production of ROS and dicarboxylic acids. These toxic compounds can damage mitochondrial outer membranes, which impairs the mitochondrial $\beta$-oxidation system. These damages directly induce the accumulation of long-chain fatty acids in hepatocytes. Furthermore, PPAR $\alpha$ activation increases the expression of FAT and FATP, which promotes the influx of fatty acids from blood. Longchain fatty acids and their CoA esters accumulated in hepatocytes are likely to act as potent detergents, which further damages the outer membranes of mitochondria. Fatty acids and their derivatives function as natural ligands of PPAR $\alpha$, which results in the activation of PPAR $\alpha$ and the induction of FAT, FATP, AOX, and CYP4A1, which further accelerates mitochondrial damage, the reduction of mitochondrial $\beta$-oxidation activity, and the accumulation of fatty acids in a vicious cycle.

Persistent PPAR $\alpha$ activation increases oxidative DNA damage because of a disproportionate increase in ROS-generating enzymes relative to the levels of degrading enzymes such as catalase and SOD, which can predispose hepatocytes to malignant transformation. In addition, persistent PPAR $\alpha$ activation leads to increased 
Table 2

Primer pairs used for RT-PCR

\begin{tabular}{|c|c|c|c|c|}
\hline Gene & $\begin{array}{c}\text { GeneBank } \\
\text { accession } \\
\text { number }\end{array}$ & & Primer sequence & $\begin{array}{l}\text { Product } \\
\text { (bp) }\end{array}$ \\
\hline ACC & NM_133360 & $\begin{array}{l}F \\
R\end{array}$ & $\begin{array}{l}\text { 5'-GGGCACAGACCGTGGTAGTT-3' } \\
\text { 5'-CAGGATCAGCTGGGATACTGAGT-3' }\end{array}$ & 105 \\
\hline ApoB & NM_009693 & $\begin{array}{l}\mathrm{F} \\
\mathrm{R}\end{array}$ & $\begin{array}{l}\text { 5'-TCACCCCCGGGATCAAG-3' } \\
\text { 5'-TCCAAGGACACAGAGGGCTTT-3' }\end{array}$ & 85 \\
\hline AOX & NM_015729 & $\begin{array}{l}\mathrm{F} \\
\mathrm{R}\end{array}$ & $\begin{array}{l}\text { 5'-TGGTATGGTGTCGTACTTGAATGAC-3' } \\
\text { 5'-AATTTCTACCAATCTGGCTGCAC-3' }\end{array}$ & 145 \\
\hline FAS & NM_007988 & $\begin{array}{l}F \\
R\end{array}$ & $\begin{array}{l}\text { 5'-ATCCTGGAACGAGAACACGATCT-3' } \\
\text { 5'-AGAGACGTGTCACTCCTGGACTT-3' }\end{array}$ & 140 \\
\hline FAT & NM_007643 & $\begin{array}{l}\mathrm{F} \\
\mathrm{R}\end{array}$ & $\begin{array}{l}\text { 5'-CCAAATGAAGATGAGCATAGGACAT-3' } \\
\text { 5'-GTTGACCTGCAGTCGTTTTGC-3' }\end{array}$ & 87 \\
\hline FATP & NM_011977 & $\begin{array}{l}\mathrm{F} \\
\mathrm{R}\end{array}$ & $\begin{array}{l}\text { 5'-ACCACCGGGCTTCCTAAGG-3' } \\
\text { 5'-CTGTAGGAATGGTGGCCAAAG-3' }\end{array}$ & 80 \\
\hline GAPDH & M32599 & $\begin{array}{l}F \\
R\end{array}$ & $\begin{array}{l}\text { 5'-TGCACCACCAACTGCTTAG-3' } \\
\text { 5'-GGATGCAGGGATGATGTTCTG-3' }\end{array}$ & 177 \\
\hline L-FABP & NM_017399 & $\begin{array}{l}\mathrm{F} \\
\mathrm{R}\end{array}$ & $\begin{array}{l}\text { 5'-GCAGAGCCAGGAGAACTTTGAG-3' } \\
5^{\prime} \text {-TTTGATTTTCTTCCCTTCATGCA-3' }\end{array}$ & 121 \\
\hline MCAD & NM_007382 & $\begin{array}{l}\mathrm{F} \\
\mathrm{R}\end{array}$ & $\begin{array}{l}\text { 5'-TGCTTTTGATAGAACCAGACCTACAGT-3' } \\
\text { 5'-CTTGGTGCTCCACTAGCAGCTT-3' }\end{array}$ & 128 \\
\hline MTP & NM_008642 & $\begin{array}{l}F \\
R\end{array}$ & $\begin{array}{l}\text { 5'-GAGCGGTCTGGATTTACAACG-3' } \\
\text { 5'-GTAGGTAGTGACAGATGTGGCTTTTG-3' }\end{array}$ & 72 \\
\hline PPAR $\alpha$ & NM_011144 & $\begin{array}{l}\mathrm{F} \\
\mathrm{R}\end{array}$ & $\begin{array}{l}\text { 5'-CCTCAGGGTACCACTACGGAGT-3' } \\
5^{\prime} \text {-GCCGAATAGTTCGCCGAA-3' }\end{array}$ & 69 \\
\hline
\end{tabular}

$F$, forward sequence; $R$, reverse sequence.

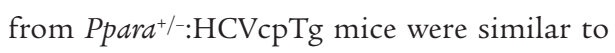
those from Ppara-/-:HCVcpTg mice, which demonstrates that the presence of functional PPAR $\alpha$ itself is not a prerequisite for the occurrence of steatosis and HCC induced by the HCV core protein. Moreover, a comparison between $\mathrm{Ppara}^{+/-}$: $\mathrm{HCV} \mathrm{cpTg}$ and $\mathrm{Ppara}^{+/+}: \mathrm{HCV} \mathrm{cpTg}$ mice uncovered an unexpected and important fact that the core protein-dependent pathological changes do not appear without significant activation of PPAR $\alpha$. Thus, it is not the presence of PPAR $\alpha$ per se, but rather a high level of PPAR $\alpha$ activation that seems to be essential for the development of HCV core protein-induced steatosis and HCC.

To reinforce the abovementioned hypothesis, $\mathrm{Ppara}^{+/-}$and $\mathrm{Ppara}^{+/-}: \mathrm{HCV}$ cpTg mice were treated with an exogenous PPAR agonist, clofibrate, for 24 months. In $\mathrm{Ppara}^{+/-}$mice, longterm clofibrate treatment caused a certain level of persistent PPAR $\alpha$ activation and a low incidence of HCC. Interestingly, in $\mathrm{Ppara}^{+/}$: $\mathrm{HCV} c \mathrm{TT}$ mice, clofibrate treatment induced more intensive PPAR $\alpha$ activation and HCC at a much higher incidence, accompanied by damaged mitochondrial outer membranes, severe steatosis, and decreased mitochondrial $\beta$-oxidation activity. The results from the clofibratetreated $\mathrm{Ppara}^{+/-}: \mathrm{HCV} \mathrm{cpTg}$ mice were similar to those of the Ppara $^{+/+}:$HCV cpTg mice not treated with clofibrate. Therefore, these findings fur-

cell division, as revealed by the expression of cell cycle regulators such as cyclin D1 and CDK4. Furthermore, there is little change in apoptosis, which, under normal circumstances, would remove damaged cells capable of undergoing transformation. Thus, under these conditions, it is plausible that some aberrant hepatocytes do not undergo apoptosis and develop into HCC.

It is well known that chronic activation of PPAR $\alpha$ is associated with hepatocarcinogenesis in mice exposed to peroxisome proliferators or in mice lacking AOX expression. The common clinicopathological characteristics of HCC in these mice are multicentric HCC $(20,22,36,37)$, the well-differentiated appearance of HCC including trabecular features and often a "nodule-in-nodule" pattern (22, $36,37)$, and no evidence of fibrosis or cirrhosis in the nonneoplastic liver parenchyma $(22,36)$, similar to that observed in $\mathrm{Ppara}^{+/+}$: HCVcpTg mice. However, mice chronically exposed to peroxisome proliferators are clearly distinct from $\mathrm{Ppara}^{+/+}: \mathrm{HCV} \mathrm{cpTg}$ mice in that they have normal mitochondrial organization, increased mitochondrial $\beta$-oxidation activity, and no steatosis $(16,36)$. AOX-null mice are also different from $\mathrm{Ppara}^{+/+}: \mathrm{HCV}$ cpTg mice with respect to mitochondrial structure (22). These detailed comparisons between the 3 mouse models reveal the importance of mitochondrial abnormalities in the pathogenesis of HCV-related diseases.

PPAR $\alpha$ is known to regulate the hepatic expression of many proteins associated with fatty acid and triglyceride metabolism, cell division and apoptosis, oxidative stress generation and degradation, and so forth $(15,16,20,21,24-26)$; therefore, complete deletion of the PPAR $\alpha$ gene from mice might cause hitherto unknown influences on the pathways involved in the development of hepatic steatosis and HCC. To consider these unknown effects, $\mathrm{Para}^{+/-}: \mathrm{HCV}$ cpTg mice were adopted in the current study. Surprisingly, almost all results ther support the concept that a long-term and high level of PPAR $\alpha$ activation is necessary for steatogenesis and hepatocarcinogenesis in HCVcpTg mice and emphasize the significant role of the HCV core protein as a PPAR $\alpha$ coactivator in vivo.

A pulse-chase experiment showed that PPAR $\alpha$ was stabilized in hepatocyte nuclei in mice expressing the HCV core protein. Many nuclear receptors, including PPAR $\alpha$ and $\operatorname{RXR} \alpha$, are known to be degraded by the ubiquitin-proteasome system (38), which plays an important role in modulating the activity of nuclear receptors. Further studies will be needed to clarify whether the core protein influences the ubiquitin-proteasome pathway.

Recent studies have shown conflicting result, i.e., that PPAR $\alpha$ was downregulated in the livers of chronic hepatitis C patients (39, 40). Although the association between PPAR $\alpha$ function and chronic $\mathrm{HCV}$ infection remains a matter of controversy in humans, the changes observed in the transgenic mice resemble in many ways the clinicopathological features of chronically HCV-infected patients; both show a high frequency of accompanying steatosis $(10,40,41)$, increased accumulation of carbon 18 monounsaturated fatty acids in the liver (42), mitochondrial dysfunction (43), increased insulin resistance (44) and oxidative stress $(45,46)$, male-preferential (2) and multicentric occurrence of $\operatorname{HCC}(47,48)$, and the well-differentiated appearance of HCC, including trabecular features and often a "nodule-in-nodule" pattern $(47,48)$. Thus, it is postulated that the mechanism of steatogenesis and hepatocarcinogenesis we proposed may partially apply to patients with chronic HCV infection. If so, therapeutic interventions to alleviate persistent and excessive PPAR $\alpha$ activation might be beneficial in the prevention of HCC. To clarify the exact relationship between PPAR $\alpha$ activation and HCV-induced hepatocarcinogenesis in humans, further 
experiments using noncancerous liver tissues obtained from $\mathrm{HCV}$ related HCC patients and using mice carrying human PPAR $\alpha$ and $\mathrm{HCV}$ core protein genes are needed.

In conclusion, we clarified for the first time that persistent and potent PPAR $\alpha$ activation is absolutely required for the development of severe steatosis and HCC induced by HCV core protein. In addition, we uncovered paradoxical and specific functions of PPAR $\alpha$ in the mechanism of steatogenesis mediated by the core protein. Our results offer clues in the search for novel therapeutic and nutritional management options, especially with respect to neutral lipids, for chronically HCV-infected patients.

\section{Methods}

Mice. The generation of HCVcpTg mice and Ppara-/- mice was described previously $(7,24,49)$. Male HCVcpTg mice and female Ppara/- mice were mated, and $\mathrm{F} 1$ mice bearing the $\mathrm{HCV}$ core protein gene were intercrossed to produce F2 mice. $\mathrm{Ppara}^{+/+}, \mathrm{Ppara}^{+/}$, and $\mathrm{Ppara}{ }^{-/}$mice bearing the HCV core protein gene, designated as Ppara ${ }^{+/+}: \mathrm{HCV} c \mathrm{Tg}, \mathrm{Ppara}^{+/-}: \mathrm{HCV} \mathrm{CpTg}$, and Pparal-: $\mathrm{HCV} c \mathrm{Tg}$ mice, in the F4 generation were subjected to serial analyses. Because HCC develops preferentially in male HCVcpTg mice (9), male mice were analyzed. Age-matched male $\mathrm{Para}^{+/+}$mice without the core protein gene were used as controls. For identifying genotypes, genomic DNA was isolated from mouse tails and amplified by PCR. Primer pairs were designed as described elsewhere: 5'-GCCCACAGGACGTTAAGTTC-3' and 5'-TAGTTCACGCCGTCCTCCAG-3' for the HCV core gene (7) and 5'-CAGAGCAACCATCCAGATGA-3' and 5'-AAACGCAACGTAGAGTGCTG-3' for the PPAR $\alpha$ gene (24). Amplified alleles for HCV core and PPAR $\alpha$ genes were 460 and 472 base pairs, respectively. Five mice per cage were fed a routine diet and were kept free of specific pathogens according to institutional guidelines. For the clofibrate treatment experiments, 2-month-old male $\mathrm{Ppara}^{+/-}$and $\mathrm{Ppara}^{+/-}: \mathrm{HCVcpTg}$ mice were randomly divided into 2 groups $(n=20$ in each group) and were fed either a routine diet or one containing $0.05 \%(\mathrm{w} / \mathrm{w})$ clofibrate (Wako Pure Chemicals Industries) for 24 months. All mice were killed by cervical dislocation before their livers were excised. If a hepatic tumor was present, the tumor was removed and subjected to histological analysis, and the remaining liver tissues were used for biochemical analyses. All animal experiments were conducted in accordance with animal study protocols outlined in the Guide for the Care and Use of Laboratory Animals prepared by the National Academy of Sciences and approved by the Shinshu University School of Medicine.

Preparation of nuclear, mitochondrial, and cytosolic fractions. Approximately $400 \mathrm{mg}$ of liver tissue was minced on ice and transferred to $10 \%(\mathrm{w} / \mathrm{v})$ isolation buffer $(250 \mathrm{mM}$ sucrose in $10 \mathrm{mM}$ Tris- $\mathrm{HCl}$ [pH 7.4] and $0.5 \mathrm{mM}$ EGTA and $0.1 \%$ bovine serum albumin [ $\mathrm{pH} 7.4]$ ). The samples were gently homogenized by $10-20$ strokes with a chilled Dounce homogenizer (Wheaton) and loose-fitting pestle. The homogenate was centrifuged at $500 \times \mathrm{g}$ for $5 \mathrm{~min}$ at $4^{\circ} \mathrm{C}$. The supernatant was retained, and the resulting pellet was resuspended with isolation buffer and centrifuged at 4,500 $\mathrm{g}$ for $10 \mathrm{~min}$ at $4^{\circ} \mathrm{C}$. The pellet fraction was suspended again and centrifuged at $20,000 \times g$ for $1 \mathrm{~h}$ at $4^{\circ} \mathrm{C}$, and the resulting pellet was used as the nuclear fraction. The combined supernatant fractions were centrifuged at 7,800 $\times \mathrm{g}$ for $10 \mathrm{~min}$ at $4^{\circ} \mathrm{C}$ to obtain a crude mitochondria pellet. This pellet was resuspended with isolation buffer, centrifuged at 7,800 $\times \mathrm{g}$ for $10 \mathrm{~min}$ at $4^{\circ} \mathrm{C}$, and used as the mitochondrial fraction. Finally, all supernatant fractions were collected and centrifuged at $20,000 \times \mathrm{g}$ for $30 \mathrm{~min}$ at $4^{\circ} \mathrm{C}$, and the resulting supernatant was used as the cytosolic fraction.

Immunoblot analysis. Protein concentrations were measured colorimetrically with a BCA Protein Assay kit (Pierce). For the analysis of fatty acidmetabolizing enzymes, hepatocyte mitochondrial fractions or whole-liver lysates $(20 \mu \mathrm{g}$ protein) were subjected to $10 \%$ SDS-PAGE (16). For analysis of PPAR $\alpha$, nuclear fractions (100 $\mu \mathrm{g}$ protein) were used. For analysis of other proteins, whole lysates or cytosolic fractions ( $50 \mu \mathrm{g}$ protein) were subjected to electrophoresis. After electrophoresis, the proteins were transferred to nitrocellulose membranes, which were incubated with the primary antibody and then with alkaline phosphatase-conjugated goat anti-rabbit or antimouse IgG. Antibodies against $\mathrm{HCV}$ core protein, fatty acid-metabolizing enzymes, CYP4A1, catalase, and PPAR $\alpha$ were described previously $(9,16,24$, 50). Antibodies against other proteins were purchased commercially: cytochrome $c$ antibody from BD Transduction Laboratories and other antibodies from Santa Cruz Biotechnology. The band of actin or histone H1 was used as the loading control. The band intensity was measured densitometrically, normalized to that of actin or histone H1, and subsequently expressed as fold changes relative to that of $\mathrm{Ppara}^{+/+}$nontransgenic mice.

Analysis of $m R N A$. Total liver RNA was extracted using an RNeasy Mini Kit (Qiagen), and cDNA was generated by SuperScript II reverse transcriptase (Gibco BRL). Quantitative RT-PCR was performed using a SYBR green PCR kit and an ABI Prism 7700 Sequence Detection System (Applied Biosystems). The primer pairs used for RT-PCR are shown in Table 2. The mRNA level was normalized to the GAPDH mRNA level and subsequently expressed as fold changes relative to that of $\mathrm{Para}^{+/+}$nontransgenic mice.

Light microscopy and immunohistochemical analysis. Small blocks of liver tissue from each mouse were fixed in $10 \%$ formalin in phosphate-buffered saline and embedded in paraffin. Sections ( $4 \mu \mathrm{m}$ thick) were stained with hematoxylin and eosin. For immunohistochemical localization of PCNA and 8-OHdG, other small blocks of liver tissue were fixed in $4 \%$ paraformaldehyde in phosphate-buffered saline. Sections ( $4 \mu \mathrm{m}$ thick) then were affixed to glass slides and incubated overnight with mouse monoclonal antibodies against PCNA (1:100 dilution; Santa Cruz) or 8-OHdG (1:10 dilution; Japan Institute for the Control of Aging). Sections were immunostained using EnVision+ kit, with 3,3'-diaminobenzidine as a substrate (DAKO). Hepatocytes positive for PCNA or 8-OHdG were examined in 10 randomly selected $\times 400$ microscopic fields per section. Two-thousand hepatocytes were examined for each mouse, and the number of immunostained hepatocyte nuclei was expressed as a percentage.

Assessment of hepatocyte apoptosis. TUNEL assay was performed using a MEBSTAIN Apoptosis Kit II (Medical \& Biological Laboratories). Two thousand hepatocytes were examined for each mouse, and the number of TUNEL-positive hepatocytes was expressed as a percentage.

Pulse-label and pulse-chase experiments. Parenchymal hepatocytes were isolated by the modified in situ perfusion method (51). After perfusion with $0.05 \%$ collagenase solution (Wako), the isolated hepatocytes were washed 3 times by means of differential centrifugation and the dead cells were removed by density-gradient centrifugation at $500 \mathrm{~g}$ for $3 \mathrm{~min}$ at $4{ }^{\circ} \mathrm{C}$ on Percoll (Amersham Pharmacia Biotech). The live hepatocytes were washed and suspended in William's E medium containing 5\% FBS. When the viability of the isolated hepatocytes exceeded $85 \%$ as determined by the trypan blue exclusion test, the following experiments were conducted. The isolated hepatocytes were washed twice and incubated in methionine-free medium containing $5 \%$ dialyzed FBS for $1 \mathrm{~h}$ at $37^{\circ} \mathrm{C}$. The medium was replaced with the same medium containing $300 \mathrm{mCi} / \mathrm{ml}$ of $\left[{ }^{35} \mathrm{~S}\right]$ methionine (Amersham Pharmacia Biotech). After a 3-h incubation, the labeled medium was exchanged for the standard medium, and the preparation was chased for 3, 6, or $12 \mathrm{~h}$. The labeled cells were washed, homogenized, and centrifuged at $800 \mathrm{~g}$ for $5 \mathrm{~min}$ at $4^{\circ} \mathrm{C}$ to obtain a crude nucleus pellet. This pellet was resuspended with isolation buffer and centrifuged at $20,000 \mathrm{~g}$ for $1 \mathrm{~h}$ at $4^{\circ} \mathrm{C}$ to prepare the nuclear fraction. The levels of radioactivity in the homogenates of the pulse-labeled preparations were similar between the transgenic and the nontransgenic mice, which suggested that the $\left.{ }^{[35} \mathrm{S}\right]$ methionine uptake capacity in the former hepatocytes was similar to that in the latter. The nuclear fraction was lysed in RIPA buffer $(10 \mathrm{mM}$ Tris-HCl, $\mathrm{pH} 7.4 ; 0.2 \%$ sodium deoxycholate, $0.2 \%$ Nonidet P- $40,0.1 \%$ SDS, 
$0.25 \mathrm{mM}$ PMSF, and $10 \mathrm{mg} / \mathrm{ml}$ aprotinin). The lysate was incubated for $3 \mathrm{~h}$ at $4^{\circ} \mathrm{C}$ with purified anti-PPAR $\alpha$ antibody. The immune complexes were precipitated with Staphylococcus aureus protein A bound to agarose beads. After the precipitates had been washed in RIPA buffer, the labeled proteins were resolved by $10 \%$ SDS-PAGE and visualized by autoradiography.

Analysis of fatty acid uptake ability. Assays for fatty acid uptake were carried out according to a method reported by Graulet et al. (52) with minor modifications. Briefly, 3 mice in each group were fasted overnight. Livers were removed quickly, rinsed in ice-cold saline solution, and cut into $500-\mu \mathrm{m}$ thick slices with an Oxford Vibratome (Oxford Laboratories). Approximately $150 \mathrm{mg}$ of fresh liver (6-8 liver slices) was placed on stainless steel grids positioned in a $25-\mathrm{ml}$ flask equipped with suspended plastic center wells (Kontes) and incubated in RPMI-1640 medium (Sigma-Aldrich) devoid of fatty acids for $2 \mathrm{~h}$ at $37^{\circ} \mathrm{C}$. The medium was then replaced with fresh RPMI-1640 medium supplemented with an antibiotic-antimycotic cocktail and $0.8 \mathrm{mM}\left[1-{ }^{14} \mathrm{C}\right]$ palmitic acid $(4 \mathrm{mCi} / \mathrm{mmol})$ (American Radiolabeled Chemicals) complexed to BSA (palmitic acid:albumin molar ratio of 4:1). After a 7 -h incubation, the medium was collected and slices were washed with $2 \mathrm{ml}$ of saline solution and homogenized in Tris buffer $(25 \mathrm{mM}$ Tris- $\mathrm{HCl}, \mathrm{pH} 8.0 ; 50 \mathrm{mM} \mathrm{NaCl})$. Fatty acid uptake ability was calculated as the sum of palmitic acid converted to $\mathrm{CO}_{2}$ and ketone bodies with that incorporated into total cellular lipids after incubation. For measurement of $\mathrm{CO}_{2}$ production by the liver slices, the center wells were placed into scintillation vials containing $4 \mathrm{ml}$ of scintillation cocktail, and radioactivity was counted. For measurement of ketone body generation, aliquots of medium $(500 \mu \mathrm{l})$ and liver homogenates $(250 \mu \mathrm{l})$ were treated with ice-cold perchloric acid to make final concentrations of $200 \mathrm{mM}$ and were centrifuged at $3,000 \mathrm{~g}$ for $20 \mathrm{~min}$ at $4^{\circ} \mathrm{C}$. Aliquots of the supernatant containing the ketone bodies were introduced into the scintillation vials, and radioactivity was counted. Total cellular lipids were extracted from the liver homogenates according to a modified method developed by Folch et al. (53), collected into scintillation vials, and evaporated to dryness under an air stream; radioactivity was then counted. The experiment was repeated 3 times, and palmitic acid uptake ability was expressed as fold changes relative to that of $\mathrm{Ppara}^{+/+}$nontransgenic mice.

Other methods. To determine the hepatic content of lipids and lipid peroxides, lipids were extracted according to a method by Folch et al. (53). Triglycerides and free fatty acids were measured with a Triglyceride E-test kit and a NEFA C-test kit (Wako), respectively. Lipid peroxides (malondialdeyde and 4-hydroxyalkenals) were measured using an LPO-586 kit (OXIS International). Hepatic $\beta$-oxidation activity was determined as described previously (16). Hepatic caspase 3 activity was measured as described elsewhere (54). Plasma glucose and insulin levels were determined using a Glucose CII-test kit(Wako) and a mouse insulin ELISA kit(U-type,AKRIN-031; Shibayagi), respectively.

Statistics. Statistical analysis was performed with a 2-tailed Student's $t$ test for quantitative variables or with a chi-square test for qualitative variables. Quantitative data are expressed as the mean \pm SD. $P<0.05$ was considered to be statistically significant.

\section{Acknowledgments}

We thank Trevor Ralph for editorial assistance and Chikako Tanaka for helpful suggestions.

Received for publication August 13, 2007, and accepted in revised form November 7, 2007.

Address correspondence to: Naoki Tanaka, Department of Metabolic Regulation, Institute on Aging and Adaptation, Shinshu University Graduate School of Medicine, Asahi 3-1-1, Matsumoto 390-8621, Japan. Phone: 81-263-37-2850; Fax: 81-263-37-3094; E-mail: naopi@hsp.md.shinshu-u.ac.jp.
1. Kiyosawa, K., et al. 1990. Interrelationship of blood transfusion, non-A, non-B hepatitis and hepatocellular carcinoma: analysis by detection of antibody to hepatitis $C$ virus. Hepatology. 12:671-675.

2. Kiyosawa, K., et al. 2004. Hepatocellular carcinoma: recent trends in Japan. Gastroenterology. 127(5 Suppl. 1):S17-S26.

3. Tanaka, Y., et al. 2002. Inaugural article: a comparison of the molecular clock of hepatitis $C$ virus in the United States and Japan predicts that hepatocellular carcinoma incidence in the United States will increase over the next two decades. Proc. Natl. Acad. Sci. U. S. A. 99:15584-15589.

4. Okuda, K., Fujimoto, I., Hanai, A., and Urano, Y. 1987. Changing incidence of hepatocellular carcinoma in Japan. Cancer Res. 47:4967-4972.

5. El-Serag, H.B., and Mason, A.C. 1999. Rising incidence of hepatocellular carcinoma in the United States. N. Engl.J. Med. 340:745-750.

6. Shimotohno, K. 2000. Hepatitis C virus and its pathogenesis. Semin. Cancer Biol. 10:233-240.

7. Moriya, K., et al. 1997. Hepatitis C virus core protein induces hepatic steatosis in transgenic mice. J. Gen. Virol. 78:1527-1531.

8. Shintani, Y., et al. 2004. Hepatitis C virus infection and diabetes: direct involvement of the virus in the development of insulin resistance. Gastroenterology. 126:840-848.

9. Moriya, K., et al. 1998. The core protein of hepatitis $\mathrm{C}$ virus induces hepatocellular carcinoma in transgenic mice. Nat. Med. 4:1065-1068.

10. Powell, E.E., Jonsson, J.R., and Clouston, A.D. 2005. Steatosis: co-factor in other liver diseases. Hepatology. 42:5-13.

11. Ohata, K., et al. 2003. Hepatic steatosis is a risk factor for hepatocellular carcinoma in patients with chronic hepatitis $\mathrm{C}$ virus infection. Cancer.

\section{7:3036-3043}

12. Browning, J.D., and Horton, J.D. 2004. Molecular mediators of hepatic steatosis and liver injury. J. Clin. Invest. 114:147-152.

13. Le, T.H., et al. 2004. The zonal distribution of megamitochondria with crystalline inclusions in nonalcoholic steatohepatitis. Hepatology. 39:1423-1429.

14. Yang, S., Lin, H.Z., Hwang, J., Chacko, V.P., and Diehl, A.M. 2001. Hepatic hyperplasia in noncirrhotic fatty livers: is obesity-related hepatic steatosis a premalignant condition? Cancer Res. 61:5016-5023.

15. Desvergne, B., and Wahli, W. 1999. Peroxisome proliferator-activated receptors: nuclear control of metabolism. Endocr. Rev. 20:649-688.

16. Aoyama, T., et al. 1998. Altered constitutive expression of fatty acid-metabolizing enzymes in mice lacking the peroxisome proliferator-activated receptor $\alpha$ (PPAR $\alpha)$. J. Biol. Chem. 273:5678-5684.

17. Staels, B., et al. 1998. Mechanism of action of fibrates on lipid and lipoprotein metabolism. Circulation. 98:2088-2093.

18. Harano, Y., et al. 2006. Fenofibrate, a peroxisome proliferator-activated receptor $\alpha$ agonist, reduces hepatic steatosis and lipid peroxidation in fatty liver Shionogi mice with hereditary fatty liver. Liver Int. 26:613-620.

19. Yeldandi, A.V., Rao, M.S., and Reddy, J.K. 2000. Hydrogen peroxide generation in peroxisome proliferator-induced oncogenesis. Mutat. Res. 448:159-177.

20. Yu, S., Rao, M.S., and Reddy, J.K. 2003. Peroxisome proliferator-activated receptors, fatty acid oxidation, steatohepatitis and hepatocarcinogenesis. Curr. Mol. Med. 3:561-572.

21. Peters, J.M., Cattley, R.C., and Gonzalez, F.J. 1997.
Role of PPAR $\alpha$ in the mechanism of action of the nongenotoxic carcinogen and peroxisome proliferator Wy-14,643. Carcinogenesis. 18:2029-2033.

22. Fan, C.Y., et al. 1998. Steatohepatitis, spontaneous peroxisome proliferation and liver tumors in mice lacking peroxisomal fatty acyl-CoA oxidase. Implications for peroxisome proliferator-activated receptor $\alpha$ natural ligand metabolism. J. Biol. Chem. 273:15639-15645.

23. Moriya, K., et al. 2001. Oxidative stress in the absence of inflammation in a mouse model for hepatitis $\mathrm{C}$ virus-associated hepatocarcinogenesis. Cancer Res. 61:4365-4370.

24. Lee, S.S., et al. 1995. Targeted disruption of the $\alpha$ isoform of the peroxisome proliferator-activated receptor gene in mice results in abolishment of the pleiotropic effects of peroxisome proliferators. Mol. Cell. Biol. 15:3012-3022.

25. Mandard, S., Muller, M., and Kersten, S. 2004. Peroxisome proliferator-activated receptor $\alpha$ target genes. Cell. Mol. Life Sci. 61:393-416.

26. Peters, J.M., et al. 1998. Role of peroxisome proliferator-activated receptor $\alpha$ in altered cell cycle regulation in mouse liver. Carcinogenesis. 19:1989-1994.

27. Tsutsumi, T., et al. 2002. Interaction of hepatitis $C$ virus core protein with retinoid $X$ receptor $\alpha$ modulates its transcriptional activity. Hepatology. 35:937-946.

28. Tanaka, N., et al. 2003. In vivo stabilization of nuclear retinoid $X$ receptor $\alpha$ in the presence of peroxisome proliferator-activated receptor $\alpha$. FEBS Lett. 543:120-124.

29. Moriishi, K., et al. 2007. Critical role of PA28 $\gamma$ in hepatitis $\mathrm{C}$ virus-associated steatogenesis and hepatocarcinogenesis. Proc. Natl. Acad. Sci. U. S. A. 104:1661-1666.

30. Perlemuter, G., et al. 2002. Hepatitis C virus core 
protein inhibits microsomal triglyceride transfer protein activity and very low density lipoprotein secretion: a model of viral-related steatosis. FASEBJ. 16:185-194

31. Korenaga, M., et al. 2005. Hepatitis C virus core protein inhibits mitochondrial electron transport and increases reactive oxygen species (ROS) production. J. Biol. Chem. 280:37481-37488.

32. Gomez-Gonzalo, M., et al. 2004. Hepatitis C virus core protein regulates $\mathrm{p} 300 / \mathrm{CBP}$ co-activation function. Possible role in the regulation of NF-AT1 transcriptional activity. Virology. 328:120-130.

33. Yu, S., and Reddy, J.K. 2007. Transcription coactivators for peroxisome proliferator-activated receptors. Biochim. Biophys. Acta. 1771:936-951.

34. Spaziani, A., Alisi, A., Sanna, D., and Balsano, C. 2006. Role of 38 MAPK and RNA-dependent protein kinase (PKR) in hepatitis $\mathrm{C}$ virus core-dependent nuclear delocalization of cyclin B1. J. Biol. Chem. 281:10983-10989.

35. Diradourian, C., Girard, J., and Pegorier, J.P. 2005. Phosphorylation of PPARs: from molecular characterization to physiological relevance. Biochimie. 87:33-38.

36. Reddy, J.K., Rao, M.S., Azarnoff, D.L., and Sell, S. 1979. Mitogenic and carcinogenic effects of a hypolipidemic peroxisome proliferator, [4-chloro6-(2,3-xylidino)-2- pyrimidinylthio]acetic acid (Wy-14,643), in rat and mouse liver. Cancer Res. 39:152-161.

37. Rao, M.S., and Reddy, J.K. 1996. Hepatocarcinogenesis of peroxisome proliferators. Ann. N. Y. Acad. Sci. 804:573-587.
38. Genini, D., and Catapano, C.V. 2006. Control of peroxisome proliferator-activated receptor fate by the ubiquitin-proteasome system. J. Recept. Signal. Transduct. Res. 26:679-692.

39. Dharancy, S., et al. 2005. Impaired expression of the peroxisome proliferator-activated receptor alpha during hepatitis C virus infection. Gastroenterology. 128:334-342.

40. de Gottardi, A., et al. 2006. Peroxisome proliferator-activated receptor-alpha and-gamma mRNA levels are reduced in chronic hepatitis $\mathrm{C}$ with steatosis and genotype 3 infection. Aliment. Pharmacol. Ther. 23:107-114.

41. Lefkowitch, J.H., et al. 1993. Pathological diagnosis of chronic hepatitis $\mathrm{C}$ : a multicenter comparative study with chronic hepatitis B. Gastroenterology. 104:595-603.

42. Moriya, K., et al. 2001. Increase in the concentration of carbon 18 monounsaturated fatty acids in the liver with hepatitis $\mathrm{C}$ : analysis in transgenic mice and humans. Biochem. Biophys. Res. Commun. 281:1207-1212.

43. Barbaro, G., et al. 1999. Hepatocellular mitochondrial alterations in patients with chronic hepatitis C: ultrastructural and biochemical findings. Am.J. Gastroenterol. 94:2198-2205.

44. Hui, J.M., et al. 2003. Insulin resistance is associated with chronic hepatitis $\mathrm{C}$ virus infection and fibrosis progression [corrected]. Gastroenterology. 125:1695-1704.

45. Kato, J., et al. 2001. Normalization of elevated hepatic 8-hydroxy-2'-deoxyguanosine levels in chronic hepatitis $\mathrm{C}$ patients by phlebotomy and low iron diet. Cancer Res. 61:8697-8702.

46. Horiike, S., et al. 2005. Accumulation of 8-nitroguanine in the liver of patients with chronic hepatitis C. J. Hepatol. 43:403-410.

47. Takenaka, K., et al. 1994. Possible multicentric occurrence of hepatocellular carcinoma: a clinicopathological study. Hepatology. 19:889-894.

48. Oikawa, T., et al. 2005. Multistep and multicentric development of hepatocellular carcinoma: histological analysis of 980 resected nodules. J. Hepatol. 42:225-229.

49. Akiyama, T.E., et al. 2001. Peroxisome proliferatoractivated receptor- $\alpha$ regulates lipid homeostasis, but is not associated with obesity. J. Biol. Chem. 276:39088-39093.

50. Nakajima, T., et al. 2004. Peroxisome proliferator-activated receptor $\alpha$ protects against alcoholinduced liver damage. Hepatology. 40:972-980.

51. Ni, R., et al. 1994. Fas-mediated apoptosis in primary cultured mouse hepatocytes. Exp. Cell Res. 215:332-337.

52. Graulet, B., Gruffat, D., Durand, D., and Bauchart, D. 1998. Fatty acid metabolism and very low density lipoprotein secretion in liver slices from rats and preruminant calves. J. Biochem. 124:1212-1219.

53. Folch, J., Lees, M., and Sloane Stanley, G.H. 1957. A simple method for the isolation and purification of total lipids from animal tissues. J. Biol. Chem. 226:497-509.

54. Gurtu, V., Kain, S.R., and Zhang, G. 1997. Fluorometric and colorimetric detection of caspase activity associated with apoptosis. Anal. Biochem. 251:98-102. 